\title{
Biomarkers in Urachal Cancer and Adenocarcinomas in the Bladder: A Comprehensive Review Supplemented by Own Data
}

\author{
Henning Reis $\left(\mathrm{D},{ }^{1}\right.$ Ulrich Krafft, ${ }^{2}$ Christian Niedworok, ${ }^{2}$ Orsolya Módos, ${ }^{3}$ Thomas Herold, \\ Mark Behrendt, ${ }^{4}$ Hikmat Al-Ahmadie, ${ }^{5}$ Boris Hadaschik, ${ }^{2}$ Peter Nyirady, ${ }^{3}$ \\ and Tibor Szarvas ${ }^{2,3}$ \\ ${ }^{1}$ Institute of Pathology, University Hospital Essen, University of Duisburg-Essen, Hufelandstr 55, 45147 Essen, Germany \\ ${ }^{2}$ Department of Urology, University Hospital Essen, University of Duisburg-Essen, Hufelandstr 55, 45147 Essen, Germany \\ ${ }^{3}$ Department of Urology, Semmelweis University, Üllöi út 78/b, 1082 Budapest, Hungary \\ ${ }^{4}$ Department of Urology, The Netherlands Cancer Institute - Antoni van Leeuwenhoek Hospital, Plesmanlaan 121, \\ 1066 CX Amsterdam, Netherlands \\ ${ }^{5}$ Department of Pathology, Memorial Sloan Kettering Cancer Center, 1275 York Avenue, New York, NY 10065, USA
}

Correspondence should be addressed to Henning Reis; henning.reis@t-online.de

Received 25 July 2017; Accepted 6 February 2018; Published 12 March 2018

Academic Editor: Tilman Todenhöfer

Copyright (c) 2018 Henning Reis et al. This is an open access article distributed under the Creative Commons Attribution License, which permits unrestricted use, distribution, and reproduction in any medium, provided the original work is properly cited.

Urachal cancer $(\mathrm{UrC})$ is a rare but aggressive cancer. Due to overlapping histomorphology, discrimination of urachal from primary bladder adenocarcinomas (PBAC) and adenocarcinomas secondarily involving the bladder (particularly colorectal adenocarcinomas, CRC) can be challenging. Therefore, we aimed to give an overview of helpful (immunohistochemical) biomarkers and clinicopathological factors in addition to survival analyses and included institutional data from 12 urachal adenocarcinomas. A PubMed search yielded 319 suitable studies since 1930 in the English literature with 1984 cases of UrC including 1834 adenocarcinomas (92\%) and 150 nonadenocarcinomas (8\%). UrC was more common in men (63\%), showed a median age at diagnosis of 50.8 years and a median tumor size of $6.0 \mathrm{~cm}$. No associations were noted for overall survival and progression-free survival (PFS) and clinicopathological factors beside a favorable PFS in male patients $(p=0.047)$. The immunohistochemical markers found to be potentially helpful in the differential diagnostic situation are AMACR and CK34 $\beta$ E12 (UrC versus CRC and PBAC), CK7, $\beta$-Catenin and CD15 (UrC and PBAC versus CRC), and CEA and GATA3 (UrC and CRC versus PBAC). Serum markers like CEA, CA19-9 and CA125 might additionally be useful in the follow-up and monitoring of UrC.

\section{Introduction}

The urachus is a remnant of the fetal structure connecting the allantois and the fetal bladder. During early fetal development, the urachus usually regresses to form an obliterated fibromuscular canal, known as the median umbilical ligament [1-4]. Failure of complete luminal obliteration has been described in up to one-third of adults and can rarely lead to various anomalies including cysts, fistulas, and diverticula or rarely malignant transformation $[2,5]$.
Our understanding of urachal cancer ( $\mathrm{UrC}$ ) has evolved since the seminal studies by Begg [6] in the 1930's following the first report by Hue and Jacquin [7] in 1863 and earlier works of Cullen in 1916 [8]. UrC is a very rare but highly malignant tumor entity with an incidence of $<1 \%$ of all bladder cancers $[1,9,10]$. Establishing the diagnosis of $\operatorname{UrC}$ can be challenging for the urologist, pathologist, and radiologist and usually requires a multidisciplinary approach. In terms of histopathology, many overlapping features with the main differential diagnostic entities exist. While the diagnostic 
criteria adapted and established by Sheldon et al. [11] are most widely used, Gopalan and colleagues [1] modified these criteria and Paner and colleagues proposed diagnostic criteria for nonglandular type UrC [12].

Recently, Paner and colleagues also gave a review on the diagnosis and classification of urachal epithelial neoplasms [13]. To furthermore give a current overview of the clinical and therapeutical implications of $\mathrm{UrC}$, we have recently conducted a meta-analysis of the literature including 1010 cases of UrC [14].

Histologically, urachal adenocarcinomas (which are the most common carcinomas of urachal origin) overlap with their main differential diagnostic entities, that is, primary bladder adenocarcinomas and colorectal adenocarcinomas. The present work therefore aims to provide an overview and summary of the immunohistochemical biomarkers in $\mathrm{UrC}$ and their potential role in the diagnosis of such tumors. It is combined with clinicopathological evidence and its data is collected from the published literature since 1930. Additionally, it is supported by our own data of immunohistochemical expression in 12 UrC cases with 11 different antibodies including the report of GATA3 expression in this disease.

\section{Literature Review and Statistics}

A PubMed search was conducted using the string ["urachus carcinoma" OR "urachus cancer" OR "urachal carcinoma" OR "urachal cancer"] which returned 854 results (end of data acquisition: 08/2016). The algorithm of study selection is illustrated in Figure 1. Information was extracted from whole papers written in English language and from English abstracts in case of other primary language. In case of different entities in the papers, only information regarding $\mathrm{UrC}$ was extracted. When available, survival data was recorded for both overall survival (OS) and progression-free survival (PFS). For statistical analyses, SPSS (v23; IBM, Armonk, USA) was used. Pearson correlation analysis was conducted when appropriate. Survival analyses were conducted using the Kaplan Meier method with the log-rank test and univariable Cox analysis. When appropriate, continuous variables were dichotomized at their median level for analysis of their impact on survival.

\section{Additional Data from Our Own Institution}

The clinicopathological data of our cohort has been published previously [15]. Immunohistochemical studies were performed on formalin-fixed and paraffin-embedded urachal adenocarcinoma tissue using a BenchMark ULTRA System (Ventana Medical Systems, Tucson, USA) following manufacturer's instructions. A total of 11 different antibodies were performed on 12 cases of urachal adenocarcinomas from the University Hospital of Essen including $\beta$-Catenin, CD15, CDX2, CEA, CK7, CK20, GATA3, MLH1, MSH2, MSH6, and PMS2 (Supplementary Table 1). The study was approved by the ethic committee of the University Hospital of Essen (16-6902-BO, 04.28.2016).
Further details on used antibodies, protocol information, and results of the immunohistochemical analyses are displayed in Supplementary Table 1.

\section{General Results of the Literature Review}

Three hundred and nineteen studies were identified that contained sufficient information on cases of UrC. The number of publications has increased rapidly in the recent years with 169 (53\%) publications since the year 2000 and 75 (24\%) studies from 2011-2016.

A total of 2154 cases of UrC were identified, with information on UrC histology available in 1984 cases (92\%), of which 1834 (92\%) were adenocarcinomas. The majority of studies with information on $\mathrm{UrC}$ cases were case reports (74\%), while contributing only a minor part to the total number of cases (16\%). In 1491 cases, gender information was available with evidence showing that most UrC cases occurred in men (63\%) compared to women (37\%). The mean and median age were 48.6 and 50.8 years, respectively (range: $0.3-86.0$ years), and tumor size $7.1 \mathrm{~cm}$ and $6.0 \mathrm{~cm}$, respectively (range: $0.5-25.0 \mathrm{~cm}$ ). Data on tumor grades were sporadic and inconsistent and could not be further analyzed. Survival data were available in 76 cases (adenocarcinomas: $n=60$, nonadenocarcinomas: $n=16$ ) with a median followup of 12 months in the total cohort (range: 1-62 months). The median OS for the entire cohort was 46.8 months (adenocarcinomas: 42.7 months) with a 1-year survival of $86 \%$ (adenocarcinomas: 86\%), 3-year survival of 63\% (adenocarcinomas: $59 \%$ ), and a 5-year survival of $41 \%$ (adenocarcinomas: $35 \%)$. The median PFS for the entire cohort was 46.6 months (adenocarcinomas: 41.1 months) and $75 \%$ at 1-year (adenocarcinomas: 72\%), 60\% at 3 years (adenocarcinomas: $55 \%$ ), and $39 \%$ at 5 years (adenocarcinomas: $33 \%$ ). It is important to note that some of the survival data derives from older papers with different treatment strategies that might have affected the outcome analysis. In fact, recent epidemiological studies demonstrate higher survival rates (5-year overall survival of approximately 50\%) due to advances in the surgical and medical management of this disease [16].

Detailed clinicopathological data are listed in Table 1. Data on UrC adenocarcinomas were collected from these references $[1,3,4,9-11,15-251]$.

\section{Specific Review Data: Adenocarcinomas}

Histopathologically, both primary adenocarcinomas of the bladder and urachal adenocarcinomas show similar subtypes although their distribution differs $[21,252,253]$. In invasive urachal adenocarcinoma, the following four subtypes are described in the 2016 WHO classification: mucinous (colloidal) type with preponderance of extracellular mucin and malignant epithelia floating within, enteric (intestinal) type with preponderance of malignant stratified epithelium resembling colorectal adenocarcinomas, mixed type with neither a mucinous nor an enteric pattern prevailing, not other specified (NOS) type with a pattern not easily identifiable as 


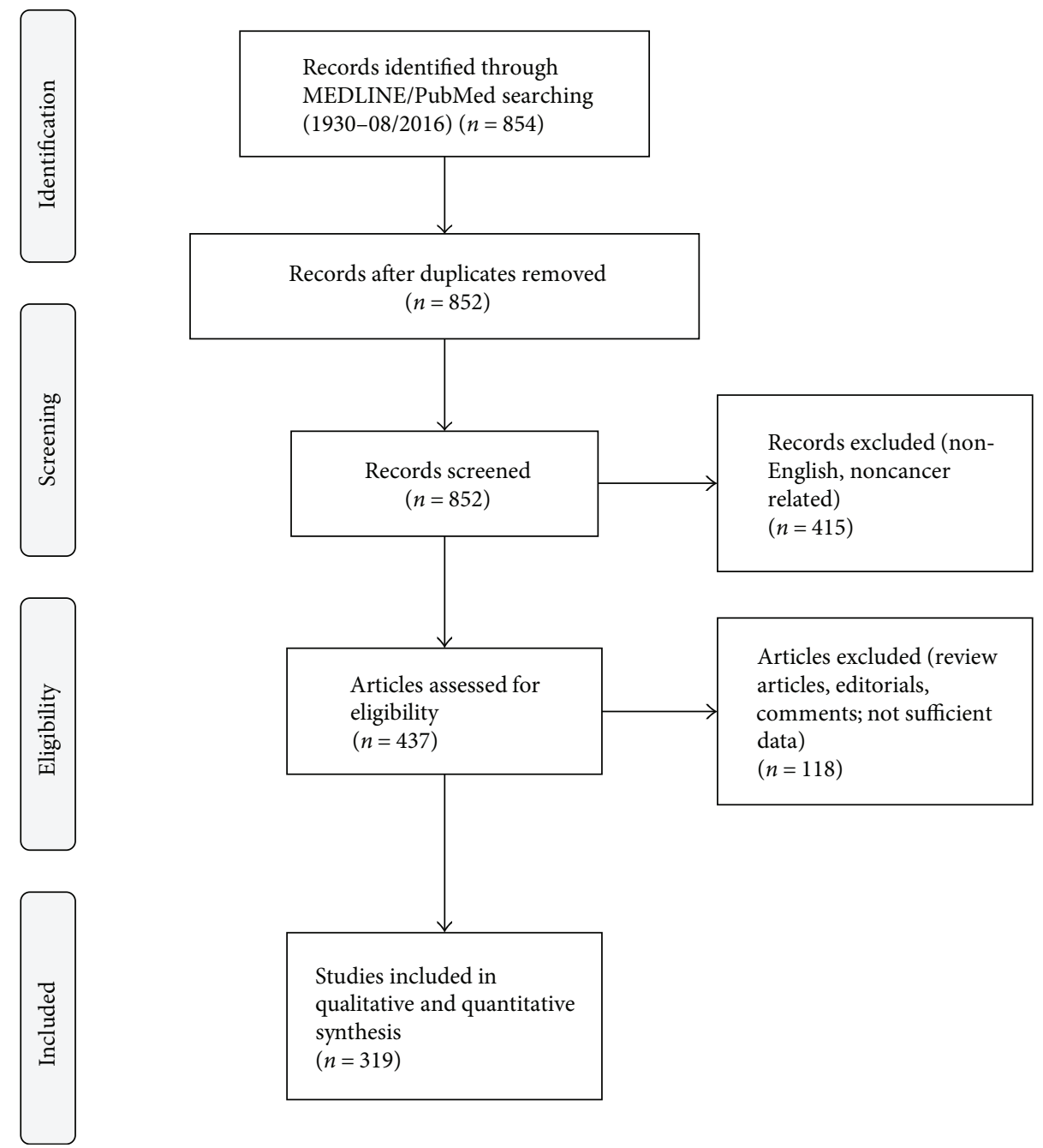

FIgURE 1: PRISMA flow diagram. The diagram illustrates the phases and selection criteria used for study selection in this work.

mucinous or enteric type, and signet ring cell type with signet ring cell morphology prevailing.

It is important to note that the concept of mucinous cystic tumors as recently proposed by Amin et al. [17] was not applied for this study due to the lack of such a classification in the older literature. In their work, Amin et al. described a distinct subgroup of urachal neoplasms with predominant cystic appearance in analogy to similar neoplasms in the ovary. This includes mucinous cystadenomas, mucinous cystic tumor of low malignant potential (MCTLMP), and mucinous cystadenocarcinoma with microinvasion or frank invasion. However, although in cox analyses tumor size was not associated with survival, not larger but smaller tumor size exhibited a higher hazard ratio for OS possibly giving support to the concept of favorable prognosis of mucinous cystic lesions of urachal origin [17].

In a population-based study from Wright and colleagues including $151 \mathrm{UrC}$ adenocarcinomas and 1374 primary bladder adenocarcinomas, the mucinous/colloid pattern was detected in $48 \%$ of UrC adenocarcinomas [16]. Also in our analysis, the mucinous type represented the most common special type of urachal adenocarcinomas (57\%) (Table 1,
Figure 2(a)). In Wright and colleagues' work, the second most common pattern was the NOS type (39\%), which in our analysis accounted for $14 \%$. However, in their analysis, the enteric type was not explicitly mentioned, which comprised $15 \%$ in our study. Additionally, they described the signet ring cell type and the mixed type in $7 \%$ each, which comprised $6 \%$ and $8 \%$ in our analysis, respectively. The prognostic value of these histopathologic features, however, remains to be established while a more favorable clinical course for UrC adenocarcinomas as compared to primary bladder adenocarcinomas was found [16]. Additionally, presence of signet ring cell morphology and higher tumor grade were identified of unfavorable prognostic value in some [10, $21,157,192,221]$ but not all series [24] of UrC adenocarcinomas. Regarding signet ring cell morphology, this may result from the differing definitions and lack of consistent cut-off on the amount of signet ring cells across the different studies. In our survival analysis from cases of the literature, we could not detect an influence of type of UrC adenocarcinoma on OS, but a borderline influence on PFS in terms of a survival benefit for intestinal type UrC. However, this finding was not consistent in further (Kaplan Meier) analyses, 
TABLE 1: Review data of the cohort (a) and in association with survival data (b). UrC: urachal cancer; NOS: not otherwise specified; n/a: data not available; UC: urothelial carcinoma; SCC: squamous cell carcinoma; npl.: neoplasms; HR: hazard ratio; CI: confidence interval; ref.: reference group. ${ }^{*}$ Data analysis was not feasible due to insufficient number of cases; ${ }^{\wedge}$ Cut-off values were chosen after partition tests.

(a)

\begin{tabular}{|c|c|c|}
\hline & $n$ & $\%$ \\
\hline Studies & 319 & 100 \\
\hline Original study & 72 & 22.6 \\
\hline Case report & 235 & 73.7 \\
\hline Missing information & 12 & 3.7 \\
\hline UrC total & 1984 & 100 \\
\hline UrC adenocarcinoma total & 1834 & 100 \\
\hline UrC adenocarcinoma specific type & 1144 & 62.4 \\
\hline Mucinous & 647 & 56.6 \\
\hline Enteric & 172 & 15.0 \\
\hline NOS & 157 & 13.7 \\
\hline Mixed & 96 & 8.4 \\
\hline Signet ring & 72 & 6.3 \\
\hline UrC adenocarcinoma type n/a & 690 & 37.6 \\
\hline UrC nonadenocarcinoma & 150 & 100 \\
\hline UrC nonadenocarcinoma specific type & 124 & 82.7 \\
\hline UC & 58 & 46.8 \\
\hline Sarcoma & 34 & 27.4 \\
\hline SCC & 26 & 21.0 \\
\hline Neuroendocrine npl. & 6 & 4.8 \\
\hline UrC nonadenocarcinoma type $\mathrm{n} / \mathrm{a}$ & 26 & 17.3 \\
\hline Gender information available & 1491 & 100 \\
\hline Male & 936 & 62.8 \\
\hline Female & 555 & 37.2 \\
\hline Age (mean/median) in years & $48.6 / 50.8$ & \\
\hline Tumor size (mean/median) in $\mathrm{cm}$ & $7.1 / 6.0$ & \\
\hline
\end{tabular}

(b)

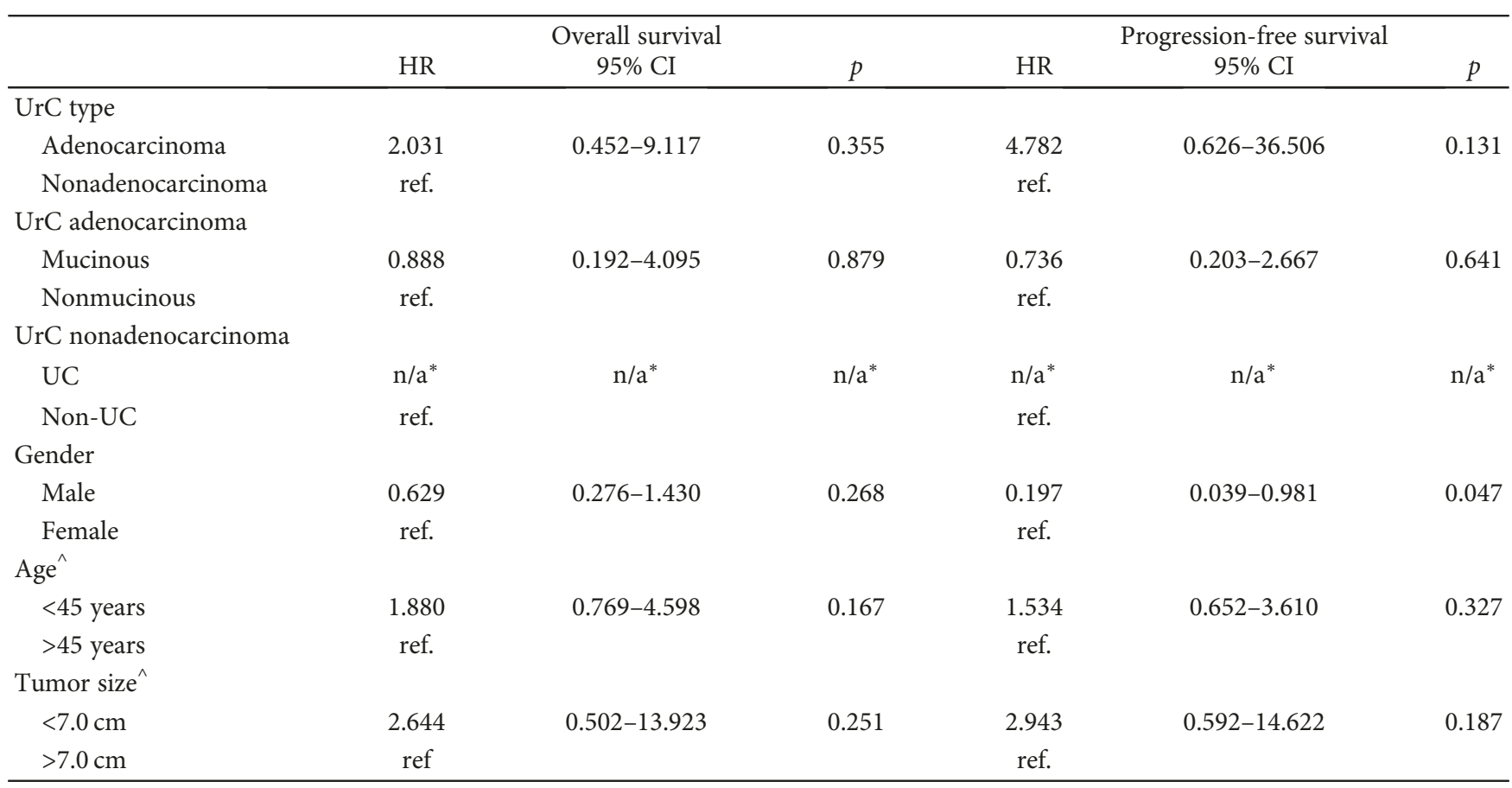




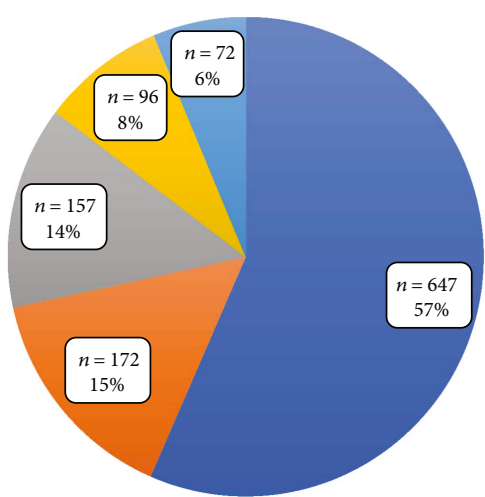

$$
\begin{aligned}
& \text { - Mucinous } \\
& \text { - Enteric } \\
& \text { nOS } \\
& \text { = Mixed } \\
& \text { - Signet ring }
\end{aligned}
$$

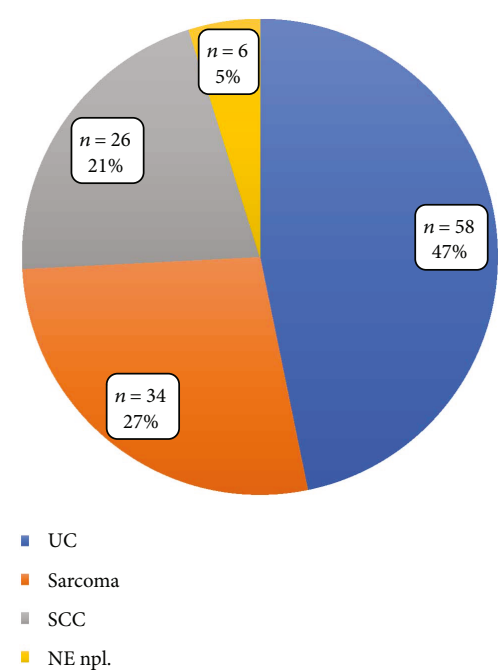

(b)

Figure 2: Distribution of the different types of UrC (a) in urachal adenocarcinomas with available information of special type and (b) in nonadenocarcinoma UrC with information of special type. UrC: urachal cancer; NOS; not otherwise specified; UC: urothelial carcinoma; SCC: squamous cell carcinoma; NE npl.: neuroendocrine neoplasms.

thus preventing further conclusions. Data density was too low for any tumor grading-related analyses.

Regarding the gender distribution, our review data is similar to epidemiological studies with preponderance of male UrC patients $(62.8 \%)$ [16]. While no significant influence of gender was detectable on OS in our accumulated data from the literature, male gender was associated with improved PFS $(p=0.047)$, an effect which was mainly related to the adenocarcinoma part of the cohort ( $p=0.009$; Supplementary Figure 1). This effect has not yet been mentioned in the literature while its cause remains to be elucidated. It seems not to be related to median tumor size or age at diagnosis as these factors were not associated with gender. Additionally, no significant prognostic associations were noted for these two factors, neither in the total cohort nor in subgroup analyses.

\section{Specific Review Data: Nonadenocarcinoma Neoplasms}

In addition to UrC adenocarcinomas, nonglandular urachal tumors are included in the recent WHO 2016 classification. These are urothelial, squamous, neuroendocrine, and mixed-type neoplasms, which are stated to account for $4 \%$ to $27 \%$ of cases $[12,13,253,254]$. These neoplasms are histologically and immunophenotypically similar to their counterparts elsewhere in the body [253].

Our analysis yielded 124 (of 150) cases of nonadenocarcinoma UrC with further classified histology. Urothelial carcinomas (UC) represented the largest group ( $n=58,47 \%)$ (Table 1, Figure 2(b)) [3, 10-12, 19, 23, 46, 71, 82, 85, 127, $223,255-267]$. The second largest group was the group of sarcomas $(n=34,27 \%)$, however, with a large variety of different entities including childhood rhabdomyosarcoma (embryonal, alveolar and NOS types) [268-272], leiomyosarcomas [273-276], fibrosarcomas [277, 278], and also some cases without further specification of the type of entity
$[3,11,47,279-281]$. Attention has to be paid to the fact that the reported sarcomas derive from a broad timespan with different knowledge levels, respectively. Therefore, some of these neoplasms would today be classified differently. In addition to mesenchymal lesions, our analysis showed 26 cases of squamous cell carcinomas (SCC; 21\%) [11, 71, 85, $105,223,282-291]$, followed by neuroendocrine neoplasms including small cell carcinomas with 6 cases (5\%) $[9,10$, $12,201]$. In the remaining cases, information on nonadenocarcinoma entity was at least partly missing $[3,11,19,71,85$, $141,292,293$ ] or included other entities such as yolk sac tumors [187, 294, 295] or a neuroblastoma [296].

In addition to malignant urachal tumors, several other intermediate and benign tumors or conditions of the urachus have been reported some mimicking urachal cancer and thus posing a differential diagnostic problem. Tumors or conditions rated as intermediate include inflammatory myofibroblastic tumors (IMT) [297-300], a solitary fibrous tumor (SFT) [301], desmoid fibromatoses [302, 303], a hemangiopericytoma [304], and a Castleman's disease [305], while benign tumors and conditions include dermoid cysts [301, 306], teratomas [307, 308], leiomyomas [309, 310], (fibrous) hamartomas [311, 312], a hemangioma [313], a fibroadenoma [314], malakoplakia [315], abscesses [316-318], a xanthogranulomatous urachitis [319], a urachal tuberculosis [320], actinomycosis [321-323], an endometriosis [324], a perforated colonic diverticulitis [325], and even a fishbone within an urachal cyst [326].

\section{Biomarkers in Urachal Cancer: Immunohistochemistry}

Given the extensively overlapping histopathological features of adenocarcinomas of urachal and primary bladder origin on the one hand and secondary adenocarcinomas from different sites on the other, biomarkers for differential 
diagnostic purposes are required. The most important differential diagnostic problems with significant impact on therapeutic decisions may be categorized as follows:

(1) Differentiation between invasion/metastasis of colorectal adenocarcinomas and urachal adenocarcinomas. Exclusion of a possible invasion of this cancer (to the bladder) is a necessary step for the definitive diagnosis of $\mathrm{UrC}$ and of therapeutic relevance.

(2) Distinguishing urachal adenocarcinomas from those of primary bladder origin has also a direct clinical impact on the surgical treatment. In localized disease, primary bladder adenocarcinomas are usually treated with complete cystectomy while urachal adenocarcinomas mostly require partial cystectomy with en bloc removal of the umbilical ligament and umbilicus (radical versus partial cystectomy) with significantly different impact on quality of life $[4,85]$.

(3) Identification of the origin of a (mucinous) adenocarcinoma of unknown primary is also important as urachal adenocarcinomas frequently metastasize to various organs, such as the bone, lung, and liver. Identification of urachal origin of a (mucinous) adenocarcinoma can have a direct therapeutic consequence [4].

An overview of the immunohistochemical markers assessed in urachal adenocarcinomas is provided in Table 2 and a representative example is illustrated in Figure 3. Further detailed information is provided in Supplementary Table 2.

The immunohistochemical markers most often employed in the work up of adenocarcinomas of different sites usually include Cytokeratin 20 (CK20) and CK7. In our analysis of a total of 116 urachal adenocarcinomas, only 4 cases were negative for CK20-an overall positive rate of $97 \%[1,17$, $23,26,27,31,36,48,56,60,62,67,74,77,86,95,99,124-$ 126, 128, 148, 156, 163, 164, 216, 217, 220, 240, 245, 251, 327]. Considering the robust CK20 expression in adenocarcinomas of sites of differential diagnostic interest, CK20 has no significant value in this setting.

In contrast, expression of CK7 in these tumors is widely variable. In urachal adenocarcinomas, CK7 exhibited a pooled reactivity rate of $51 \%$, compared to considerable lower rates in colorectal cancer $(0-38 \%$, Table 2, Supplementary Table 2) $[1,17,23,26,27,31,36,48,56,60,67,74,77,86$, $99,124,125,156,163,164,216,217,220,240,251,255,292$, $327,328]$. However, similar to urachal adenocarcinomas, primary bladder adenocarcinomas constantly exhibited relatively high CK7 reactivity rates $(33 \%-70 \%)$, thus limiting the value of CK7 in the discrimination between these two entities [23, 329].

Additionally, CK20 and CK7 were the only markers with sufficient data for survival analyses. However, no significant influence of the CK20/CK7 expression profile on OS or PFS was noted.

As a rather specific nuclear marker for intestinal epithelia and corresponding adenocarcinomas, CDX2-a homeobox gene coding for a transcription factor with intestine specificity-has been proposed for differential diagnostic considerations. However, nuclear CDX2 reactivity was evident in the majority of urachal adenocarcinomas (90\%) $[1,17,23,26,31,60,99,125,126,128,216,217,240,245$, $251,327,330]$ and many primary bladder adenocarcinomas $(13 \%-83 \%)[329,331]$. In addition to its reactivity in almost all colorectal adenocarcinomas, CDX2 immunopositivity has been detected in considerable numbers in several adenocarcinomas from different sites such as the gastrointestinal tract, pancreas, and ovary [330, 332]. Furthermore, CDX2 reactivity has been described in cystitis glandularis and intestinal metaplasia of the bladder and glandular epithelia of urachal remnants [23, 333-335]. Taken together, CDX2 is not helpful in the differential diagnosis of adenocarcinomas in the urinary bladder.

Another plausible biomarker in this context is $\beta$-Catenin, a protein involved in cell-cell adhesion and gene transcription regulation [336]. In normal cells, $\beta$-Catenin staining is restricted to the membrane/cytoplasm, while in colorectal adenocarcinomas, $\beta$-Catenin exhibits nuclear accumulation due to mutation or loss of the adenomatous polyposis coli (APC) gene then acting as a transcriptional activator [337]. While in colorectal adenocarcinomas nuclear $\beta$-Catenin expression can be found in the majority of cases, nuclear $\beta$ Catenin reactivity was detected in a low rate of primary bladder adenocarcinomas (0\%-17\%) [329, 338]. Similarly, in urachal adenocarcinomas, nuclear $\beta$-Catenin expression was a rare event. In our summary analysis, any type of nuclear $\beta$ Catenin was detected in 9 of 63 cases $(14 \%)[1,17,23,26$, $125,216,220,328]$. APC mutations, however, can be found in urachal adenocarcinomas slightly more often than the immunohistochemical results propose $[20,204]$. From a differential diagnostic point of view, nuclear $\beta$-Catenin expression may be useful in distinguishing primary bladder and urachal adenocarcinomas from secondary bladder involvement by colorectal adenocarcinomas. However, $\beta$-Catenin is of no use in the differentiation of primary bladder from urachal adenocarcinomas as both entities exhibit comparable $\beta$-Catenin staining characteristics.

Further potential markers include Claudin-18 and Reg IV, however, with no available data in primary bladder adenocarcinomas. Claudin-18 has been reported to be of diagnostic value especially in pancreatic and gastric cancer, but is rarely expressed in colorectal adenocarcinomas [339-341]. Although exhibiting a positivity rate of $53 \%$ in the total number of urachal adenocarcinomas cases, it was found to have only a low positivity rate (27\%) in enteric type urachal adenocarcinomas, thus limiting its usefulness in UrC diagnostics with regard to the largest group of intestinal-differentiated colorectal adenocarcinomas [23]. Reg IV is associated with the cellular phenotype of the intestine and expressed in various cancers with intestinal differentiation such as gastric and colorectal cancer [342]. In urachal adenocarcinomas, Reg IV expression was detected in $85 \%$ of cases arguing against its potential use in the differential diagnostics of adenocarcinomas detected in the bladder [23]. Both markers additionally failed to demonstrate diagnostic value in signet ring cell UrC compared to signet ring cell carcinoma of colorectal origin [23]. 
TABLE 2: Useful immunohistochemical antibodies in the differential diagnosis of urachal adenocarcinoma (UrC), colorectal adenocarcinoma (CRC), and primary bladder adenocarcinoma (PBAC). Loss of MMR proteins (MLH1, MSH2, MSH6, and PMS2) additionally favors colorectal over urachal adenocarcinomas. For more details on reactivity rates, number of cases, and references, please refer to Supplementary Table 2. Please note that data density is low for most antibodies limiting significance. "Highest" data quality is available for CK7, $\beta$-Catenin, and CEA.-: negative ( $0 \%$ positive); $(-)$ : mostly negative (1-25\% positive); $+/-$ : some positive $(26-50 \%$ positive); $(+)$ : mostly positive (51-75\% positive); +: positive ( $76-100 \%$ positive).

\begin{tabular}{lccccccc}
\hline & \multicolumn{3}{c}{ Reactivity } & \multicolumn{3}{c}{ Differential diagnosis } \\
Biomarker (IHC) & UrC & CRC & PBAC & UrC versus CRC and PBAC & UrC and PBAC versus CRC & UrC and CRC versus PBAC \\
\hline AMACR (p504s) & $(-)$ & + & $(+)$ & + & - & - \\
CK34ßE12 (HMWCK) & $(+)$ & $(-)$ & $+/-$ & + & + & - \\
CK7 & $(+)$ & $+/-$ & $(+)$ & - & + & - \\
$\beta$-Catenin (nuclear) & $(-)$ & + & $(-)$ & - & + & - \\
CD15 (Leu-M1) & + & + - & $(+)$ & - & - & + \\
CEA & + & + & $(+)$ & - & - & + \\
GATA3 & - & - & $(+)$ & - & + \\
\hline
\end{tabular}

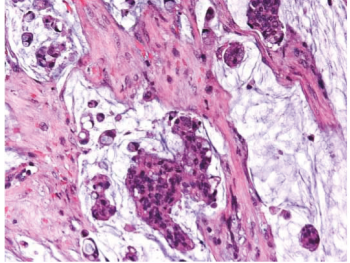

(a)

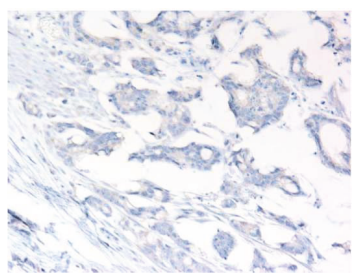

(e)

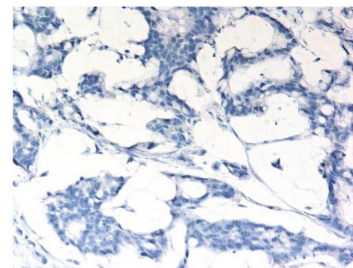

(b)

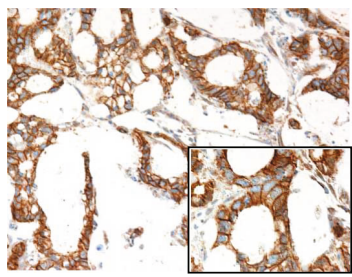

(f)

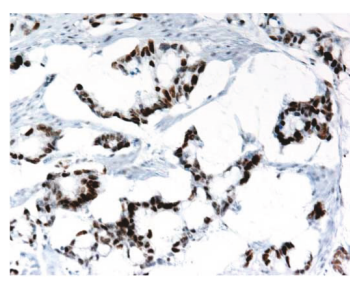

(i)

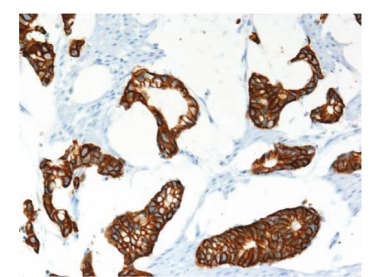

(c)

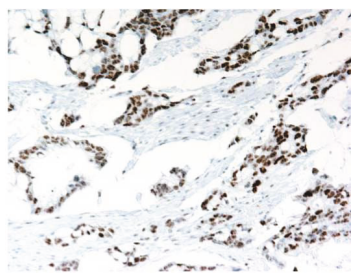

(g)

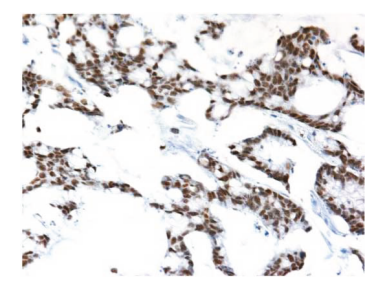

(j)

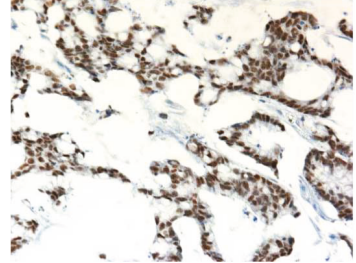

(d)

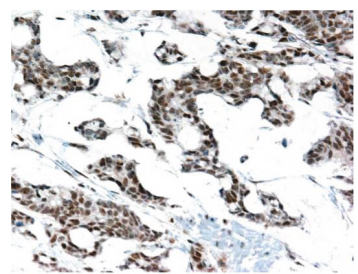

(h)

FIGURE 3: A representative case of mucinous urachal adenocarcinoma. (a) Atypical cells floating in extracellular mucin. Focal signet ring cell morphology is noticeable (H\&E staining). The case exhibited a typical profile in further immunohistochemical studies with no reactivity for CK7 (b) but positive reactivity for CK20 (c) and CDX2 (d, nuclear). As in all analyzed cases, no GATA3 reactivity was noted (e). In the $\beta$-Catenin immunohistochemistry, a strong membranous and cytoplasmic but no nuclear reactivity was noted (f; inlay magnification $600 \mathrm{x}$ ). The immunohistochemical reactions against the MMR proteins all were positive, that is, MLH1 (g), PMS2 (h), MSH2 (i), and MSH6 (j).

Further, possibly useful biomarkers of urachal adenocarcinomas with data of at least 10 cases are alpha-methylacyl-CoA racemase (AMACR, p504s), CD15 (Leu-M1), carcinoembryonic antigen (CEA), CK34ßE12 (high-molecular weight cytokeratin), GATA binding protein 3 (GATA3), mucin 2 (MUC2), and mucin 5 AC (MUC5AC).

In urachal adenocarcinomas, AMACR was found to be positive in a low number of cases (17\%), while in colorectal and primary bladder adenocarcinomas, a significantly higher number $(>66 \%)$ of cases exhibited AMACRreactivity $[17,77,343,344]$. In contrast, $C K 34 \beta E 12$ was more frequently positive (67\%) in urachal adenocarcinomas, while being variably expressed in primary bladder or colorectal adenocarcinomas $[1,26,77,125,255,345]$. A comparable distribution was detected for MUC2 and MUC5AC with high positivity rates in urachal adenocarcinomas (100\% and $92 \%)$ 
and lower rates in colorectal and primary bladder adenocarcinomas, however, with significant overlap $[86,95,100,125$, 128, 251, 335, 346, 347].

In contrast, CD15 was detected in high rates of both urachal and primary bladder adenocarcinomas (86\% and $73 \%$, resp.) compared to colorectal adenocarcinomas with a lower reactivity rate $(<50 \%)[21,27,124,125,348]$. CEA was opposingly found to be positive in all analyzed cases of urachal adenocarcinomas and in a similarly high rate of colorectal adenocarcinomas but lower rates in primary bladder adenocarcinomas (29-67\%) [21, 27, 48, 60, 67, 77, 86, 100, $106,124,163,165,245,255,348-353]$.

Finally, GATA3 was not found to be expressed in urachal adenocarcinomas and colorectal adenocarcinomas but in approximately half of cases of primary bladder adenocarcinomas $[335,354,355]$. In addition, nuclear GATA3 reactivity might be useful in the differential diagnosis of bladder adenocarcinomas with signet ring morphology [355].

The example of GATA3 in particular illustrates the need of rigorous case selection of primary bladder and/or urachal adenocarcinomas in the studies. Inclusion of UC with glandular differentiation or plasmacytoid UC could significantly weaken the validity of such a study and therefore its conclusions.

The distribution of the DNA mismatch repair (MMR) proteins, that is, MutL homolog 1 (MLH1), MutS homolog 2 (MSH2), MutS homolog 6 (MSH6), and PMS1 homolog 2 (PMS2), in the different entities might in addition also be of differential diagnostic and pathogenetic interest. While no data is available for primary bladder adenocarcinomas, sporadic colorectal adenocarcinomas exhibit a loss of MMR proteins in $10-15 \%$ in total with emphasis on MLH1 [356]. In urachal adenocarcinomas, some tumors with microsatellite instability characterized by immunohistochemistry were described [25]. We, however, detected no loss of MMR proteins by immunohistochemistry in our own institutional cases $(n=12)$. In additional preliminary molecular analyses, we also did not detect evidence of microsatellite instability (unpublished data). This seems to point to molecular differences in adenocarcinomas of urachal and colorectal origin.

Further important biomarkers in differential diagnostic considerations of adenocarcinomas in general are hormone receptors. In our review data, urachal adenocarcinomas did not express estrogen and progesterone receptors by immunohistochemistry, which might be of particular interest in the discrimination of a metastasis of urachal adenocarcinomas to the ovary and vice versa $[17,56,67]$. In this setting, the immunonegativity of urachal adenocarcinomas for cancer antigen 125 (CA125) might also be of value, however, with the limitation of only 8 cases reported in the literature $[27,60,86]$.

Low numbers of cases and no differential diagnostic value regarding the discrimination of urachal adenocarcinomas from primary bladder and colorectal adenocarcinomas were detected for $\alpha$-fetoprotein (AFP), carbohydrate antigen 19-9 (CA19-9), cluster of differentiation 10 (CD10), CK19, Das-1, E48, E-Cadherin, gross cystic disease fluid protein 15 (GCDFP15), mucin 1 (epithelial membrane antigen) (MUC1 (EMA)), mucin 6 (MUC6), Thrombmodulin, thyroid transcription factor 1 (TTF1), Uroplakin III, Villin, and Vimentin $[27,48,60,86,100,106,125,126,172,198$, 215, 217, 245, 292, 330].

However, this might not be the case for some rare and special differential diagnostic considerations as for example in the discrimination of ductal prostate cancer and the enteric type of urachal adenocarcinomas, in which immunohistochemistry for prostate specific acid phosphatase (PAP) and prostate-specific antigen (PSA) (both negative in urachal adenocarcinomas and positive in ductal prostate cancer) might be useful [21, 27, 74, 77, 100, 245, 255, 357].

In addition to the differential diagnostic context, immunohistochemical markers might be of further clinical value. We recently assessed the expression and prognostic relevance of six immunohistochemical markers (Ki67, p53, biglycan (BGN), receptor for hyaluronan-mediated motility (RHAMM), and insulin-like growth factor II mRNA binding protein 3 (IMP3)) in urachal adenocarcinomas. RHAMM, IMP3, Ki67, and p53 were found to be increased in urachal adenocarcinomas. However, none of the analyzed markers exhibited any prognostic information [15].

Although immunohistochemical biomarkers are widely used in differential diagnostic considerations, their interpretation is per se subjective. This applies in every situation in which these markers are used and therefore also in the immunohistochemical differential diagnosis of UrC. A further limitation of the collected data might also be the threshold at which the authors of the different source studies called an immunohistochemical marker positive or negative. Oftentimes, this information is missing while it can be very important. For example, the decision to call a case positive for nuclear $\beta$-Catenin might depend only on a few stained tumor nuclei but with important differential diagnostic implications [23, 329].

These considerations and also the partly overlapping positivity rates of the different immunohistochemical biomarkers make it difficult to recommend a step wise biomarker-guided approach. This could create a false sense of sensitivity and specificity of the biomarkers in the different situations. From our experience, immunohistochemical staining of a panel of antibodies, which depends on the differential diagnostic setting (Table 2), is the best way to come to a conclusion in this setting. This process might of course also include the use of further antibodies in addition to the core panel and always lies in the expertise of the diagnostic histopathologist.

\section{Biomarkers in Urachal Cancer: Serum Markers}

The (histomorphological) parallels between urachal and colorectal adenocarcinomas furthermore gave the rationale to test colorectal tumor markers in serum samples of patients with urachal adenocarcinomas, especially CEA, CA19-9, and CA125. In CRC, these markers are elevated in approximately one third (CA125), half (CA19-9), and two-thirds (CEA) of patients with a considerable variance depending on tumor size and other variables [358]. In primary bladder adenocarcinomas, however, only sporadic 
data is available with reports of elevated serum levels of these markers [359, 360].

In urachal adenocarcinomas, 44 studies including data on serum parameters were available, including 7 original studies and 37 case reports with a total of 140 patients.

Siefker-Radtke and colleagues reported on the largest cohort and found elevated $(>3 \mathrm{ng} / \mathrm{ml}$ ) CEA serum levels in $59 \%$ of patients with urachal adenocarcinomas (median: $36 \mathrm{ng} / \mathrm{ml}$ ) [24]. In 5 cases, CEA also decreased in response to chemotherapy, suggesting the potential utility of CEA testing in monitoring (or follow-up) of UrC. When analyzing the literature, elevated CEA serum levels were reported in $55.7 \%$ $(59 / 106)$ of patients at the time of diagnosis $[24,26,33,42$, $60,67,79,80,86,88,89,95,99,106,118,128,131,149$, $156,163-165,167,179,196,200,207,208,212,214,240$, $241,244,246,251]$. In our analyses, elevated CEA levels at diagnosis were associated with worse OS $(p=0.008)$ and PFS $(p=0.009)$ in dichotomized analyses (elevated versus normal), however, with only sparse survival data.

Additionally, elevated serum levels of CA19-9 and CA125 were reported in 50.8\% (31/61) and 51.4\% (19/37), respectively $[24,26,33,42,76,79-81,86,88,89,95,99$, $104,114,128,149,168,200,207,213,240,244,246,251]$. As with CEA, elevated levels of CA19-9 exhibited a trend towards worse OS and PFS (both $p=0.09$ ). No prognostic association was noted for CA125. In addition, elevated serum levels of CA125 did not correlate with negative immunohistochemical tissue expression, however, with a low case number $(n=8)$.

Other serum biomarkers reported in low case numbers of urachal adenocarcinomas include lactate dehydrogenase (LDH) [80, 199], cancer antigen 15-3 (CA15-3) [26, 114, 156], AFP $[16,42,95,106,156]$ with one case in a sevenmonth-old infant with a yolk sac tumor of the urachus [295], and neuron-specific enolase (NSE) [156] including one case of a neuroblastoma in a six-month-old child [296].

In summary, measurement of serum biomarkers might be useful in the follow-up and disease monitoring of $\mathrm{UrC}$.

\section{Conclusions}

We identified a total of 1984 cases of UrC from 319 suitable studies with sufficient data from the English literature with overall 1834 adenocarcinomas (92\%). While only minor variations in clinicopathological factors such as gender distribution (male preponderance), age at diagnosis, tumor size, and adenocarcinoma subtypes were noted, none of these factors were associated with overall survival. However, regarding progression-free survival, an advantage for male patients especially in the adenocarcinoma cohort was noted, while no such association was observed for nonglandular neoplasms of urachal origin.

The summary of existing evidence on immunohistochemical markers supplemented with our own data highlighted a differential diagnostic role for AMACR, CK34 $\beta$ E12, CK7, $\beta$-Catenin, CD15, and CEA (Table 2) which can be helpful in the routine differential diagnostic workup of adenocarcinomas in the bladder. Also, GATA3 might be helpful in the differentiation of urachal from primary bladder adenocarcinomas, with data presented almost exclusively derived from our institutional cohort. In addition, serum markers such as CEA, CA19-9, and CA125 might be useful in the follow-up and monitoring of $\mathrm{UrC}$ while CEA and CA19-9 may also be of prognostic value.

\section{Conflicts of Interest}

The authors declare that they have no conflicts of interest.

\section{Acknowledgments}

Tibor Szarvas was supported by János Bolyai Research Scholarship of the Hungarian Academy of Sciences. Gabriele Ladwig and Isabel Albertz are thanked for their skillful work.

\section{Supplementary Materials}

Supplementary Table 1(a): Detailed information on used antibodies and protocol in the cohort of the $\mathrm{UrC}$ register of the University Hospital of Essen. Supplementary Table 1(b): IHC results in the analyzed cohort of the UrC register of the University Hospital of Essen Detection of any immunoreactivity in the tumor cells was assessed as positive and complete lack of immunoreactivity as negative. For $\beta$ Catenin, the nuclear (nuc.) and membranous/cytoplasmic $(\mathrm{m} / \mathrm{c})$ reactivities were analyzed separately. The DNA mismatch repair proteins MLH1, MSH2, MSH6, and PMS2 were evaluated as positive if more than $10 \%$ of tumor cells exhibited a nuclear immunoreactivity. Specific immunostaining was cytoplasmic in case of CD15, CEA, CK7, and CK20 and nuclear in case of CDX2 and GATA3. Supplementary Table 2: detailed information on immunohistochemical biomarker expression in urachal adenocarcinomas (UrC ADC) including own data $(*)$ in comparison to figures from the literature for colorectal (CRC) and primary bladder adenocarcinomas (PBAC). This table includes information about markers of potential differential diagnostic usefulness in UrC versus CRC and PBAC, UrC and PBAC versus CRC, and $\mathrm{UrC}$ and $\mathrm{CRC}$ versus PBAC. $\wedge$ is positive in hepatoid carcinomas of the urinary bladder [329]; $\wedge \wedge$ is usually positive in clear cell PBAC [329]; $\wedge \wedge \wedge$ Figures for sporadic colorectal cancer (nonhereditary), total loss of MMR proteins is evident in $10-15 \%$ of sporadic colorectal cancers [356] * Own data from the UrC register of the University Hospital of Essen is included to increase data quality (all: $n=12$, but CK7: $n=11$ ). [15] UrC: urachal cancer; ADC: adenocarcinoma; AFP: $\alpha$-fetoprotein; AMACR: alphamethylacyl-CoA racemase; mem/cyt: membranous/cytoplasmic immunoreactivity; $\beta$-Catenin: $\beta$-Catenin; CA19-9: carbohydrate antigen 19-9; CA125: cancer antigen 125; CD10: cluster of differentiation 10; CD15: cluster of differentiation 15; CDX2: caudal-type homeobox protein 2; CEA: carcinoembryonic antigen; CK7: cytokeratin 7; CK19: cytokeratin 19; CK20: cytokeratin 20; CK34 $\beta \mathrm{E} 12$ (HMWCK): cytokeratin $34(1,5,10,14)$ (high-molecular weight cytokeratin); ER: estrogen receptor; GATA3: GATA binding protein 3; GCDFP15: Gross cystic disease fluid protein 15; HER2: human epidermal growth factor receptor 2; MMR: DNA mismatch repair proteins; MLH1: mutL homolog 1; 
MSH2: mutS homolog 2; MSH6: mutS homolog 6; MUC1 (EMA): mucin 1, cell surface associated (epithelial membrane antigen); MUC2: mucin 2, oligomeric mucus/gel-forming; MUC5AC: mucin 5AC oligomeric mucus/gel-forming; MUC6: mucin 6, oligomeric mucus/gel-forming; PR: progesterone receptor; PSAP: prostatic specific acid phosphatase; PSA: prostate-specific antigen; PMS2: PMS1 homolog 2; RegIV: Regenerating gene IV; TTF1: thyroid transcription factor 1 (NK2 homeobox 1). Supplementary Figure 1: progression-free survival in urachal adenocarcinomas regarding gender $[1,15,17,21,23,25-27,31,36,48,56,60,62,67,74$, $77,86,95,99,100,106,124-126,128,148,156,163-165,172$, $198,215-217,220,221,240,245,251,255,292,327-335,338-$ 355, 361-388]. (Supplementary Materials)

\section{References}

[1] A. Gopalan, D. S. Sharp, S. W. Fine et al., "Urachal carcinoma: a clinicopathologic analysis of 24 cases with outcome correlation," The American Journal of Surgical Pathology, vol. 33, no. 5, pp. 659-668, 2009.

[2] V. Upadhyay and A. Kukkady, "Urachal remnants: an enigma," European Journal of Pediatric Surgery, vol. 13, no. 6, pp. 372-376, 2003.

[3] J. R. Molina, J. F. Quevedo, A. F. Furth, R. L. Richardson, H. Zincke, and P. A. Burch, "Predictors of survival from urachal cancer: a Mayo Clinic study of 49 cases," Cancer, vol. 110, no. 11, pp. 2434-2440, 2007.

[4] R. A. Ashley, B. A. Inman, T. J. Sebo et al., "Urachal carcinoma: clinicopathologic features and long-term outcomes of an aggressive malignancy," Cancer, vol. 107, no. 4, pp. 712-720, 2006.

[5] G. E. Schubert, M. B. Pavkovic, and B. A. Bethke-Bedurftig, "Tubular urachal remnants in adult bladders," The Journal of Urology, vol. 127, no. 1, pp. 40-42, 1982.

[6] R. C. Begg, "The Urachus: its anatomy, histology and development," Journal of Anatomy, vol. 64, Part 2, pp. 170-183, 1930.

[7] L. Hue and M. Jacquin, "Cancer colloide de la lombille et de paroi abdominale anterieure ayant envahi la vessie," Union Med de la Siene-Inf Rouen, vol. 6, pp. 418-420, 1863.

[8] T. B. Cullen, Embryology, Anatomy, and Diseases of the Umbilicus Together with Diseases of the Urachus, W. B. SAUNDERS COMPANY, Philadelphia, PA, USA, 1916.

[9] D. E. Johnson, G. B. Hodge, F. W. Abdul-Karim, and A. G. Ayala, "Urachal carcinoma," Urology, vol. 26, no. 3, pp. 218-221, 1985.

[10] J. H. Pinthus, R. Haddad, J. Trachtenberg et al., "Population based survival data on urachal tumors," The Journal of Urology, vol. 175, no. 6, pp. 2042-2047, 2006.

[11] C. A. Sheldon, R. V. Clayman, R. Gonzalez, R. D. Williams, and E. E. Fraley, "Malignant urachal lesions," The Journal of Urology, vol. 131, no. 1, pp. 1-8, 1984.

[12] G. P. Paner, G. A. Barkan, V. Mehta et al., "Urachal carcinomas of the nonglandular type: salient features and considerations in pathologic diagnosis," The American Journal of Surgical Pathology, vol. 36, no. 3, pp. 432-442, 2012.

[13] G. P. Paner, A. Lopez-Beltran, D. Sirohi, and M. B. Amin, "Updates in the pathologic diagnosis and classification of epithelial neoplasms of urachal origin," Advances in Anatomic Pathology, vol. 23, no. 2, pp. 71-83, 2016.
[14] T. Szarvas, O. Modos, C. Niedworok et al., "Clinical, prognostic, and therapeutic aspects of urachal carcinoma-a comprehensive review with meta-analysis of 1,010 cases," Urologic Oncology, vol. 34, no. 9, pp. 388-398, 2016.

[15] C. Niedworok, M. Panitz, T. Szarvas et al., "Urachal carcinoma of the bladder: impact of clinical and immunohistochemical parameters on prognosis," The Journal of Urology, vol. 195, no. 6, pp. 1690-1696, 2016.

[16] J. L. Wright, M. P. Porter, C. I. Li, P. H. Lange, and D. W. Lin, "Differences in survival among patients with urachal and nonurachal adenocarcinomas of the bladder," Cancer, vol. 107, no. 4, pp. 721-728, 2006.

[17] M. B. Amin, S. C. Smith, J. N. Eble et al., "Glandular neoplasms of the urachus: a report of 55 cases emphasizing mucinous cystic tumors with proposed classification," The American Journal of Surgical Pathology, vol. 38, no. 8, pp. 1033-1045, 2014.

[18] R. A. Ashley, B. A. Inman, J. C. Routh, A. L. Rohlinger, D. A. Husmann, and S. A. Kramer, "Urachal anomalies: a longitudinal study of urachal remnants in children and adults," The Journal of Urology, vol. 178, no. 4, pp. 16151618, 2007.

[19] H. M. Bruins, O. Visser, M. Ploeg, C. A. Hulsbergen-van de Kaa, L. A. L. M. Kiemeney, and J. A. Witjes, "The clinical epidemiology of urachal carcinoma: results of a large, population based study," The Journal of Urology, vol. 188, no. 4, pp. 1102-1107, 2012.

[20] A. Collazo-Lorduy, M. Castillo-Martin, L. Wang et al., "Urachal carcinoma shares genomic alterations with colorectal carcinoma and may respond to epidermal growth factor inhibition," European Urology, vol. 70, no. 5, pp. 771-775, 2016.

[21] D. J. Grignon, J. Y. Ro, A. G. Ayala, D. E. Johnson, and N. G. Ordonez, "Primary adenocarcinoma of the urinary bladder. A clinicopathologic analysis of 72 cases," Cancer, vol. 67, no. 8, pp. 2165-2172, 1991.

[22] O. Modos, H. Reis, C. Niedworok et al., "Mutations of KRAS, NRAS, BRAF, EGFR, and PIK3CA genes in urachal carcinoma: occurence and prognostic significance," Oncotarget, vol. 7, no. 26, pp. 39293-39301, 2016.

[23] G. P. Paner, J. K. McKenney, G. A. Barkan et al., "Immunohistochemical analysis in a morphologic spectrum of urachal epithelial neoplasms: diagnostic implications and pitfalls," The American Journal of Surgical Pathology, vol. 35, no. 6, pp. 787-798, 2011.

[24] A. O. Siefker-Radtke, J. Gee, Y. U. Shen et al., "Multimodality management of urachal carcinoma: the M. D. Anderson Cancer Center experience," The Journal of Urology, vol. 169, no. 4, pp. 1295-1298, 2003.

[25] S. J. Sirintrapun, M. Ward, J. Woo, and A. Cimic, "High-stage urachal adenocarcinoma can be associated with microsatellite instability and KRAS mutations," Human Pathology, vol. 45, no. 2, pp. 327-330, 2014.

[26] I. Testa, E. Verzoni, P. Grassi, M. Colecchia, F. Panzone, and G. Procopio, "Response to targeted therapy in urachal adenocarcinoma," Rare Tumors, vol. 6, no. 4, p. 5529, 2014.

[27] Torenbeek, Lagendijk, Van Diest, Bril, van de Molengraft, and Meijer, "Value of a panel of antibodies to identify the primary origin of adenocarcinomas presenting as bladder carcinoma," Histopathology, vol. 32, no. 1, pp. 20-27, 1998. 
[28] A. M. Abeygunasekera and D. D. Ranasinghe, "Urachal carcinoma," Indian Journal of Medical Research, vol. 137, p. 398, 2013.

[29] M. Alonso-Gorrea, J. A. Mompo-Sanchis, M. Jorda-Cuevas, A. Froufe, and J. F. Jiménez-Cruz, "Signet ring cell adenocarcinoma of the urachus," European Urology, vol. 11, no. 4, pp. 282-284, 1985.

[30] C. Alvarez Alvarez, J. M. Sanchez Merino, L. Busto Castanon, F. Pombo Felipe, and F. Arnal Monreal, "Mucinous adenocarcinoma of the urachus synchronic with colorectal adenocarcinoma. Value of immunohistochemistry in the differential diagnosis," Actas Urologicas Espanolas, vol. 22, no. 6, pp. 515-518, 1998.

[31] F. Z. Aly, A. Z. Tabbarah, and L. Voltaggio, "Metastatic urachal carcinoma in bronchial brush cytology," CytoJournal, vol. 10, no. 1, p. 1, 2013.

[32] M. Ando, T. Toyoshima, C. Arisawa, S. Ikegami, and T. Okano, "Urachal adenocarcinoma accompanied by a large spherical calcified mass," International Journal of Urology, vol. 2, no. 5, pp. 344-346, 1995.

[33] F. Aoun, A. Peltier, and R. van Velthoven, "Bladder sparing robot-assisted laparoscopic en bloc resection of urachus and umbilicus for urachal adenocarcinoma," Journal of Robotic Surgery, vol. 9, no. 2, pp. 167-170, 2015.

[34] C. G. Bandler and P. R. Roen, "Mucinous adenocarcinoma arising in urachal cyst and involving bladder," The Journal of Urology, vol. 64, no. 3, pp. 504-510, 1950.

[35] J. M. Barros Rodriguez, R. Fernandez Martin, J. L. Guate Ortiz et al., "Mucinous adenocarcinoma of the urachus," Actas Urologicas Espanolas, vol. 13, no. 5, pp. 399-401, 1989.

[36] H. L. Bastian, E. K. Jensen, and A. M. B. Jylling, "Urachal carcinoma with metastasis to the maxilla: the first reported case," Journal of Oral Pathology \& Medicine, vol. 30, no. 6, pp. 378380, 2001.

[37] B. R. Baumgartner, H. M. Frederick, and H. M. Austin, "Adenocarcinoma of the urachus with vesicoenteric fistula," Urologic Radiology, vol. 6, no. 1, pp. 55-57, 1984.

[38] J. K. Bennett, T. S. Trulock, and D. E. Finnerty, "Urachal adenocarcinoma presenting as vesicoenteric fistula," Urology, vol. 25, no. 3, pp. 297-299, 1985.

[39] D. Besarani, C. A. Purdie, and N. H. Townell, "Recurrent urachal adenocarcinoma," Journal of Clinical Pathology, vol. 56, no. 11, p. 882, 2003.

[40] M. L. Bobrow, "Mucoid carcinoma of the urachus," American Journal of Obstetrics and Gynecology, vol. 65, no. 4, pp. 909911, 1953.

[41] A. Boscaino, P. Sapere, and B. Marra, "Carcinoma of the urachus. Report of a case,” Tumori, vol. 75, no. 5, pp. 518-519, 1989.

[42] O. Bratu, V. Madan, C. Ilie et al., "About the urachus and its pathology. A clinical case of urachus tumor," Journal of Medicine and Life, vol. 2, no. 2, pp. 232-236, 2009.

[43] S. H. Brick, A. C. Friedman, H. M. Pollack et al., "Urachal carcinoma: CT findings," Radiology, vol. 169, no. 2, pp. 377-381, 1988.

[44] L. Busto Martin, L. Valbuena, and L. Busto Castanon, "Urachal adenocarcinoma of the bladder, our experience in 20 years," Archivos Españoles de Urología, vol. 68, no. 2, pp. 178-182, 2015.
[45] C. A. Cawker, "Mucinous adenocarcinoma of urachus, invading the urinary bladder," Canadian Medical Association Journal, vol. 57, no. 1, pp. 58-60, 1947.

[46] D. Chen, Y. Li, Z. Yu et al., "Investigating urachal carcinoma for more than 15 years," Oncology Letters, vol. 8, no. 5, pp. 2279-2283, 2014.

[47] Z. F. Chen, F. Wang, Z. K. Qin et al., "Clinical analysis of 14 cases of urachal carcinoma," Ai Zheng, vol. 27, no. 9, pp. 966969, 2008.

[48] L. Cheng, R. Montironi, and D. G. Bostwick, "Villous adenoma of the urinary tract: a report of 23 cases, including 8 with coexistent adenocarcinoma," The American Journal of Surgical Pathology, vol. 23, no. 7, pp. 764-771, 1999.

[49] S. Y. Cho, K. C. Moon, J. H. Park, C. Kwak, H. H. Kim, and J. H. Ku, "Outcomes of Korean patients with clinically localized urachal or non-urachal adenocarcinoma of the bladder," Urologic Oncology, vol. 31, no. 1, pp. 24-31, 2013.

[50] J. R. Colombo Jr, M. Desai, D. Canes et al., "Laparoscopic partial cystectomy for urachal and bladder cancer," Clinics, vol. 63, no. 6, pp. 731-734, 2008.

[51] L. R. Cooperman, "Carcinoma of urachus with extensive abdominal calcification," Urology, vol. 12, no. 5, pp. 614616, 1978.

[52] C. L. P. da Cruz, G. L. Fernandes, M. R. C. Natal, T. R. T. Taveira, P. A. Bicalho, and Y. Q. I. P. de Brito, "Urachal neoplasia: a case report," Radiologia Brasileira, vol. 47, no. 6, pp. 387-388, 2014.

[53] S. Daljeet, S. Amreek, J. Satish et al., "Signet ring cell adenocarcinoma of the urachus," International Journal of Urology, vol. 11, no. 9, pp. 785-788, 2004.

[54] N. P. Dandekar, A. V. Dalal, H. B. Tongaonkar, and M. R. Kamat, "Adenocarcinoma of bladder," European Journal of Surgical Oncology, vol. 23, no. 2, pp. 157-160, 1997.

[55] E. de Bree, A. Witkamp, M. van de Vijver, and F. Zoetmulde, "Unusual origins of pseudomyxoma peritonei," Journal of Surgical Oncology, vol. 75, no. 4, pp. 270-274, 2000.

[56] K. Dekeister, J. L. Viguier, X. Martin, A. M. Nguyen, H. Boyle, and A. Flechon, "Urachal carcinoma with choroidal, lung, lymph node, adrenal, mammary, and bone metastases and peritoneal carcinomatosis showing partial response after chemotherapy treatment with a modified docetaxel, cisplatin and 5-fluorouracil regimen," Case Reports in Oncology, vol. 9, no. 1, pp. 216-222, 2016.

[57] J. Dhillon, Y. Liang, A. M. Kamat et al., "Urachal carcinoma: a pathologic and clinical study of 46 cases," Human Pathology, vol. 46, no. 12, pp. 1808-1814, 2015.

[58] S. Ebara, Y. Kobayashi, K. Sasaki et al., "A case of metastatic urachal cancer including a neuroendocrine component treated with gemcitabine, cisplatin and paclitaxel combination chemotherapy," Acta Medica Okayama, vol. 70, no. 3, pp. 223-227, 2016.

[59] I. Efthimiou, M. Charalampos, S. Kazoulis, S. Xirakis, V. Spiros, and I. Christoulakis, "Urachal carcinoma presenting with chronic mucusuria: a case report," Cases Journal, vol. 1, no. 1, p. 288, 2008.

[60] L. Egevad, U. Hakansson, M. Grabe, and R. Ehrnstrom, "Urachal signet-cell adenocarcinoma," Scandinavian Journal of Urology and Nephrology, vol. 43, no. 1, pp. 88-91, 2009.

[61] S. Eidt, R. Hake, and J. Witt, "Colloid carcinoma of the urachus. Cytologic diagnosis and differential diagnostic classification," Pathologe, vol. 16, no. 2, pp. 139-142, 1995. 
[62] D. El Demellawy, A. Nasr, S. Alowami, and N. Escott, "Enteric type urachal adenocarcinoma: a case report," The Canadian Journal of Urology, vol. 16, no. 4, pp. 4753-4756, 2009.

[63] A. El-Ghobashy, C. Ohadike, N. Wilkinson, G. Lane, and J. D. Campbell, "Recurrent urachal mucinous adenocarcinoma presenting as bilateral ovarian tumors on cesarean delivery," International Journal of Gynecological Cancer, vol. 19, no. 9, pp. 1539-1541, 2009.

[64] C. Elser, J. Sweet, S. K. Cheran, M. A. Haider, M. Jewett, and S. S. Sridhar, "A case of metastatic urachal adenocarcinoma treated with several different chemotherapeutic regimens," Canadian Urological Association Journal, vol. 6, no. 1, pp. E27-E31, 2012.

[65] A. C. Fahed, D. Nonaka, J. A. Kanofsky, and W. C. Huang, "Cystic mucinous tumors of the urachus: carcinoma in situ or adenoma of unknown malignant potential?," The Canadian Journal of Urology, vol. 19, no. 3, pp. 63106313, 2012.

[66] T. T. Fancher, S. J. Dudrick, and J. A. Palesty, "Papillary adenocarcinoma of the urachus presenting as an umbilical mass," Connecticut Medicine, vol. 74, no. 6, pp. 325-327, 2010.

[67] D. M. Fanning, M. Sabah, P. J. Conlon, G. J. Mellotte, M. G. Donovan, and D. M. Little, "An unusual case of cancer of the urachal remnant following repair of bladder exstrophy," Irish Journal of Medical Science, vol. 180, no. 4, pp. 913915, 2011.

[68] L. Fiter, F. Gimeno, L. Martin, and L. Gomez Tejeda, "Signetring cell adenocarcinoma of bladder," Urology, vol. 41, no. 1, pp. 30-33, 1993.

[69] S. Fujiwara, T. Takaki, T. Hikita, H. Kanzaki, and S. Kuroiwa, "Brain metastasis from urachal carcinoma," Surgical Neurology, vol. 29, no. 6, pp. 475-476, 1988.

[70] S. K. Ganguli, "Urachal carcinoma," Urology, vol. 13, no. 3, pp. 306-307, 1979.

[71] M. Ghazizadeh, S. Yamamoto, and K. Kurokawa, "Clinical features of urachal carcinoma in Japan: review of 157 patients," Urological Research, vol. 11, no. 5, pp. 235-238, 1983.

[72] J. Y. Gillenwater and W. R. Sandusky, "Mucinous adenocarcinoma of the urachus," The American Surgeon, vol. 35, no. 4, pp. 267-270, 1969.

[73] G. G. Giordano, "Orbital metastasis from a urachal tumor," JAMA Ophthalmology, vol. 113, no. 4, pp. 413-415, 1995.

[74] J. I. Monzo Gardiner, M. F. Garcia, J. M. Albornoz, and F. P. Secin, "Urachal adenocarcinoma treated with robotic assisted laparoscopy partial cystectomy," Archivos Españoles de Urología, vol. 66, no. 6, pp. 608-613, 2013.

[75] J. L. Grogono and B. F. Shepheard, "Carcinoma of the urachus [summary]," Proceedings of the Royal Society of Medicine, vol. 62, p. 1125, 1969.

[76] S. Guarnaccia, V. Pais, J. Grous, and N. Spirito, "Adenocarcinoma of the urachus associated with elevated levels of CA 125," The Journal of Urology, vol. 145, no. 1, pp. 140-141, 1991.

[77] Y. S. Ha, Y. W. Kim, B. D. Min et al., "Alpha-methylacylcoenzyme a racemase-expressing urachal adenocarcinoma of the abdominal wall," Korean Journal of Urology, vol. 51, no. 7, pp. 498-500, 2010

[78] S. Y. Han and D. M. Witten, "Carcinoma of the urachus," American Journal of Roentgenology, vol. 127, no. 2, pp. 351353, 1976.
[79] Y. Hasegawa, Y. Kato, T. Wakita, N. Hayashi, and K. Tsukamoto, "Carcinoma of the urachus: a case report," Hinyokika Kiyo, vol. 51, no. 3, pp. 191-194, 2005.

[80] T. Hayashi, T. Yuasa, S. Uehara et al., "Clinical outcome of urachal cancer in Japanese patients," International Journal of Clinical Oncology, vol. 21, no. 1, pp. 133-138, 2016.

[81] D. Hayes Ryan, P. Paramanathan, N. Russell, and J. Coulter, "Primary urachal malignancy: case report and literature review," Irish Journal of Medical Science, vol. 182, no. 4, pp. 739-741, 2013.

[82] J. Hayman, "Carcinoma of the urachus," Pathology, vol. 16, no. 2, pp. 167-171, 1984.

[83] B. Helpap and G. Wegner, "Mucous adenocarcinoma of the urinary bladder (urachal carcinoma) (author's transl)," Urologe A, vol. 19, no. 2, pp. 100-103, 1980.

[84] D. R. Henly, G. M. Farrow, and H. Zincke, "Urachal cancer: role of conservative surgery," Urology, vol. 42, no. 6, pp. 635-639, 1993.

[85] H. W. Herr, B. H. Bochner, D. Sharp, G. Dalbagni, and V. E. Reuter, "Urachal carcinoma: contemporary surgical outcomes," The Journal of Urology, vol. 178, no. 1, pp. 74-78, 2007.

[86] K. Hirashima, R. Uchino, S. Kume et al., "Intra-abdominal mucinous adenocarcinoma of urachal origin: report of a case," Surgery Today, vol. 44, no. 6, pp. 1156-1160, 2014.

[87] J. D. Hom, E. B. King, R. Fraenkel, F. R. Tavel, V. E. Weldon, and T. S. Yen, "Adenocarcinoma with a neuroendocrine component arising in the urachus. A case report," Acta Cytologica, vol. 34, no. 2, pp. 269-274, 1990.

[88] S. H. Hong, J. C. Kim, and T. K. Hwang, "Laparoscopic partial cystectomy with en bloc resection of the urachus for urachal adenocarcinoma," International Journal of Urology, vol. 14, no. 10, pp. 963-965, 2007.

[89] S. Hongoh, T. Nomoto, M. Kawakami, K. Hanai, $\mathrm{H}$. Inatsuchi, and T. Terachi, "Complete response to MFAP chemotherapy for multiple lung metastases after segmental resection of urachal carcinoma: a case report," Hinyokika Kiyo, vol. 56, no. 2, pp. 107-110, 2010.

[90] M. G. Howell Jr. and A. W. Diddle, "Mucinous adenocarcinoma of the urachus in women," American Journal of Obstetrics \& Gynecology, vol. 98, no. 4, pp. 585-586, 1967.

[91] S. P. Hurwitz, E. B. Jacobson, and H. H. Ottenstein, "Mucoid adenocarcinoma of the urachus invading bladder," The Journal of Urology, vol. 65, no. 1, pp. 87-92, 1951.

[92] K. Inoue, M. Shimada, K. Saito et al., "A case of urachal carcinoma treated by TS-1/CDDP as adjuvant chemotherapy," Hinyokika Kiyo, vol. 61, no. 11, pp. 441-443, 2015.

[93] H. Ito, M. Hagiwara, T. Furuuchi et al., "A case of double cancer involving the urachus and the bladder," Hinyokika Kiyo, vol. 56, no. 1, pp. 41-43, 2010.

[94] M. Jemni, F. el Mansouri, L. Belhassine, M. Njeh, M. el Ouakdi, and M. Ayed, "Cancer of the urachus," Journal d'Urologie, vol. 98, no. 3, pp. 173-174, 1992.

[95] E. J. Jo, C. H. Choi, D. S. Bae, S. H. Park, S. R. Hong, and J. H. Lee, "Metastatic urachal carcinoma of the ovary," The Journal of Obstetrics and Gynaecology Research, vol. 37, no. 12, pp. 1833-1837, 2011.

[96] T. E. B. Johansen and P. W. Jebsen, "Carcinoma of the urachus. A case report and review of the literature," International Urology and Nephrology, vol. 25, no. 1, pp. 59-63, 1993. 
[97] H. A. Jung, J. M. Sun, S. H. Park, G. Y. Kwon, and H. Y. Lim, "Treatment outcome and relevance of palliative chemotherapy in urachal cancer," Chemotherapy, vol. 60, no. 2, pp. 73-80, 2014.

[98] T. Kaido, H. Uemura, Y. Hirao, R. Uranishi, N. Nishi, and T. Sakaki, "Brain metastases from urachal carcinoma," Journal of Clinical Neuroscience, vol. 10, no. 6, pp. 703-705, 2003.

[99] T. Kanamaru, T. Iguchi, N. Yukimatsu et al., "A case of metastatic urachal carcinoma treated with FOLFIRI (irinotecan and 5-fluorouracil/leucovorin) plus bevacizumab," Urology Case Reports, vol. 3, no. 2, pp. 9-11, 2015.

[100] H. Kato, M. Hayama, M. Kobayashi, H. Ota, and O. Nishizawa, "Large intestinal type-urachal adenocarcinoma with focal expression of prostatic specific antigen," International Journal of Urology, vol. 11, no. 11, pp. 1033-1035, 2004.

[101] S. Kawakami, Y. Kageyama, J. Yonese et al., "Successful treatment of metastatic adenocarcinoma of the urachus: report of 2 cases with more than 10-year survival," Urology, vol. 58, no. 3, p. 462, 2001.

[102] R. A. Keating, J. P. Smith, and M. J. Muhsen, "Adenocarcinoma of the urachus," Postgraduate Seminar American Urological Association North Central, pp. 110-112, 1954.

[103] M. Kebapci, S. Saylisoy, C. Can, and E. Dundar, "Radiologic findings of urachal mucinous cystadenocarcinoma causing pseudomyxoma peritonei," Japanese Journal of Radiology, vol. 30, no. 4, pp. 345-348, 2012.

[104] N. Kikuno, S. Urakami, K. Shigeno, H. Shiina, and M. Igawa, "Urachal carcinoma associated with increased carbohydrate antigen 19-9 and carcinoembryonic antigen," The Journal of Urology, vol. 166, no. 2, p. 604, 2001.

[105] I. K. Kim, J. Y. Lee, J. K. Kwon et al., "Prognostic factors for urachal cancer: a bayesian model-averaging approach," Korean Journal of Urology, vol. 55, no. 9, pp. 574-580, 2014.

[106] H. Kise, H. Kanda, N. Hayashi, K. Arima, M. Yanagawa, and J. Kawamura, " $\alpha$-fetoprotein producing urachal tumor," The Journal of Urology, vol. 163, no. 2, p. 547, 2000.

[107] K. Kitami, N. Masuda, K. Chiba, and H. Kumagai, "Carcinoma of the urachus with variable pathological findings: report of a case and review of literature," Hinyokika Kiyo, vol. 33, no. 9, pp. 1459-1464, 1987.

[108] W. M. Kohler, C. M. Naumann, M. Hamann et al., "Mucinous adenocarcinoma of the Urachus: a case report," Aktuelle Urologie, vol. 47, no. 2, pp. 141-143, 2016.

[109] Y. Kojima, Y. Yamada, H. Kamisawa, S. Sasaki, Y. Hayashi, and K. Kohri, "Complete response of a recurrent advanced urachal carcinoma treated by S-1/cisplatin combination chemotherapy," International Journal of Urology, vol. 13, no. 8, pp. 1123-1125, 2006.

[110] M. Korobkin, L. Cambier, and J. Drake, "Computed tomography of urachal carcinoma," Journal of Computer Assisted Tomography, vol. 12, no. 6, pp. 981-987, 1988.

[111] I. M. Koster, P. Cleyndert, and R. W. M. Giard, "Best cases from the AFIP: urachal carcinoma," Radiographics, vol. 29, no. 3, pp. 939-942, 2009.

[112] P. Kountourakis, A. Ardavanis, I. Mantzaris, D. Mitsaka, and G. Rigatos, "Urachal mucinous adenocarcinoma: a case report," Journal of BUON, vol. 12, no. 4, pp. 547-548, 2007.

[113] M. V. Kovylina, D. Pushkar, O. V. Zairat'iants, and P. I. Rasner, "Glandular squamous cell carcinoma of the urinary bladder," Arkhiv Patologii, vol. 68, no. 5, pp. 35-37, 2006.
[114] I. Koyama, Y. Yamazaki, R. Nakamura et al., "A case of urachal carcinoma associated with elevated levels of CA19-9," The Japanese Journal of Urology, vol. 86, no. 10, pp. 15871590, 1995.

[115] L. S. Krane, A. K. Kader, and E. A. Levine, "Cytoreductive surgery with hyperthermic intraperitoneal chemotherapy for patients with peritoneal carcinomatosis secondary to urachal adenocarcinoma," Journal of Surgical Oncology, vol. 105, no. 3, pp. 258-260, 2012.

[116] S. Krysiewicz, "Diagnosis of urachal carcinoma by computed tomography and magnetic resonance imaging," Clinical Imaging, vol. 14, no. 3, pp. 251-254, 1990.

[117] N. Kumar, D. Khosla, R. Kumar et al., "Urachal carcinoma: clinicopathological features, treatment and outcome," Journal of Cancer Research and Therapeutics, vol. 10, no. 3, pp. 571-574, 2014.

[118] H. Kume, K. Tomita, S. Takahashi, and K. Fukutani, "Irinotecan as a new agent for urachal cancer," Urologia Internationalis, vol. 76, no. 3, pp. 281-282, 2006.

[119] M. Kuniyoshi, H. Kamemoto, H. Sakai et al., "Carcinoma of the urachus-report of 4 cases," Hinyokika Kiyo, vol. 30, no. 11, pp. 1655-1663, 1984.

[120] B. W. Lamb, R. Vaidyanathan, M. Laniado, O. Karim, and H. Motiwala, "Mucinous adenocarcinoma of the urachal remnant with pseudomyxoma peritonei," Urology Journal, vol. 7, no. 2, pp. 138-139, 2010.

[121] V. Lane, "Carcinoma of the urachus," Irish Journal of Medical Science, vol. 426, pp. 268-271, 1961.

[122] J. Leborgne, C. Cousin, H. Ollivier, and J. C. Le Neel, "Cystadenocarcinoma complicating urachal cysts. A case report and review of the literature (author's transl)," Journal de Chirurgie, vol. 119, no. 1, pp. 35-41, 1982.

[123] S. H. Lee, H. H. Kitchens, and B. S. Kim, "Adenocarcinoma of the urachus: CT features," Journal of Computer Assisted Tomography, vol. 14, no. 2, pp. 232-235, 1990.

[124] S. R. Lee, H. Kang, M. H. Kang et al., "The youngest Korean case of urachal carcinoma," Case Reports in Urology, vol. 2015, Article ID 707456, 4 pages, 2015.

[125] W. Lee, "Urachal adenocarcinoma metastatic to the ovaries resembling primary ovarian mucinous carcinoma: a case report with the immunohistochemical study," International Journal of Clinical \& Experimental Pathology, vol. 4, no. 1, pp. 118-123, 2010.

[126] X. Li, S. Liu, S. Yao, and M. Wang, "A rare case of urachal mucinous adenocarcinoma detected by $18 \mathrm{~F}-\mathrm{FDG}$ PET/CT," Clinical Nuclear Medicine, vol. 40, no. 3, pp. 282-285, 2015.

[127] C. N. Lin, N. M. Lu, H. S. Chiang, and C. Kuo, "Urachal carcinoma: a report of two cases," Zhonghua Yi Xue Za Zhi, vol. 56, no. 6, pp. 436-439, 1995.

[128] Y. Liu, H. Ishibashi, M. Hirano et al., "Cytoreductive surgery plus hyperthermic intraperitoneal chemotherapy for pseudomyxoma peritonei arising from urachus," Annals of Surgical Oncology, vol. 22, no. 8, pp. 2799-2805, 2015.

[129] S. A. Loening, E. Jacobo, C. E. Hawtrey, and D. A. Culp, "Adenocarcinoma of the urachus," The Journal of Urology, vol. 119, no. 1, pp. 68-71, 1978.

[130] B. W. Loggie, R. A. Fleming, and A. A. Hosseinian, "Peritoneal carcinomatosis with urachal signet-cell adenocarcinoma," Urology, vol. 50, no. 3, pp. 446-448, 1997.

[131] C. J. Logothetis, M. L. Samuels, and S. Ogden, "Chemotherapy for adenocarcinomas of bladder and urachal origin: 
5-fluorouracil, doxorubicin, and mitomycin-C," Urology, vol. 26, no. 3, pp. 252-255, 1985.

[132] K. P. Loh, E. Mondo, E. A. Hansen et al., “Targeted therapy based on tumor genomic analyses in metastatic urachal carcinoma," Clinical Genitourinary Cancer, vol. 14, no. 4, pp. e449-e452, 2016.

[133] A. Lopez-Beltran, F. Nogales, C. H. Donne, and J. L. Sayag, "Adenocarcinoma of the urachus showing extensive calcification and stromal osseous metaplasia," Urologia Internationalis, vol. 53, no. 2, pp. 110-113, 1994.

[134] A. R. Lupetin, "Adenocarcinoma of the urachus: computed tomography diagnosis," Journal of Computed Tomography, vol. 9, no. 1, pp. 65-67, 1985.

[135] A. Lurie, S. Eisenkraft, Y. Shotland, and M. Lurie, "Mucinproducing adenocarcinoma of the bladder of urachal origin. Case report," Urologia Internationalis, vol. 38, no. 1, pp. 1215, 1983.

[136] H. Machida, E. Ueno, H. Nakazawa, M. Fujimura, and T. Kihara, "Computed tomographic appearance of urachal carcinoma associated with urachal diverticulum misdiagnosed by cystoscopy," Abdominal Imaging, vol. 33, no. 3, pp. 363-366, 2008.

[137] F. J. Mangiacapra, J. L. Scheraga, and L. A. Jones, "Mucinous colloid adenocarcinoma of the urachus," Radiographics, vol. 21, no. 4, pp. 965-969, 2001.

[138] A. Martinez, G. Ferron, E. Mery, L. Gladieff, J. P. Delord, and D. Querleu, "Peritoneal pseudomyxoma arising from the urachus," Surgical Oncology, vol. 21, no. 1, pp. 1-5, 2012.

[139] A. Martínez-Cornelio, D. Flores-López, R. F. Ojeda, J. Quintero-Becerra, and N. Hernández-Toriz, "Surgical experience with urachal carcinoma," Cirugia y Cirujanos, vol. 77, no. 1, pp. 33-38, 2009.

[140] S. McClelland 3rd, R. E. Garcia, S. E. Monaco et al., "Carcinomatous meningitis from urachal carcinoma: the first reported case," Journal of Neuro-Oncology, vol. 76, no. 2, pp. 171-174, 2006.

[141] J. J. Meeks, H. W. Herr, M. Bernstein, H. A. Al-Ahmadie, and G. Dalbagni, "Preoperative accuracy of diagnostic evaluation of the urachal mass," The Journal of Urology, vol. 189, no. 4, pp. 1260-1262, 2013.

[142] G. D. Mekras, N. L. Block, H. M. Carrion, and M. Ishikoff, "Urachal carcinoma: diagnosis by computerized axial tomography," The Journal of Urology, vol. 123, no. 2, pp. 275-277, 1980.

[143] J. Mendeloff and N. E. McSwain Jr., "Pseudomyxoma peritonei due to mucinous adenocarcinoma of the urachus," Southern Medical Journal, vol. 64, no. 4, pp. 497-498, 1971.

[144] B. Mengiardi, W. Wiesner, F. Stoffel, L. Terracciano, and P. Freitag, "Case 44: adenocarcinoma of the urachus," Radiology, vol. 222, no. 3, pp. 744-747, 2002.

[145] A. Meyer, "Adenocarcinoma of the urachus," Z Urology, vol. 47 , no. 8, pp. 512-517, 1954.

[146] P. M. Milhoua, A. Knoll, C. B. Bleustein, and R. Ghavamian, "Laparoscopic partial cystectomy for treatment of adenocarcinoma of the urachus," Urology, vol. 67, no. 2, pp. 423.e15423.e17, 2006.

[147] Y. Miyata, Y. Sagara, T. Matsuo et al., "Response of recurrent urachal cancer to gemcitabine and cisplatin therapy: a case report and literature review," Anticancer Research, vol. 31, no. 6, pp. 2335-2338, 2011.
[148] S. G. Mohile, L. Schleicher, and D. P. Petrylak, "Treatment of metastatic urachal carcinoma in an elderly woman," Nature Clinical Practice Oncology, vol. 5, no. 1, pp. 55-58, 2008.

[149] V. Monteiro and T. M. Cunha, "Urachal carcinoma: imaging findings," Acta Radiologica Short Reports, vol. 1, no. 1, pp. 13, 2012.

[150] A. E. Morato-Lopez, M. Corres-Castillo, J. Isusi-Alcazar, N. Reyes-Garcia, O. Quiroz-Castro, and J. Serna-Macias, "Morphological-metabolic evaluation of the urachal mucinous adenocarcinoma by positron emission tomographycomputed tomography (PET-CT)," Revista Española de Medicina Nuclear e Imagen Molecular, vol. 31, no. 3, pp. 145$147,2012$.

[151] A. J. Marquez Moreno, C. Gomez Rebollo, F. Antuna Calle et al., "Urachal adenocarcinoma with late brain metastases," Archivos Españoles de Urología, vol. 63, no. 7, pp. 550-554, 2010.

[152] A. Morii, Y. Furuya, Y. Fujiuchi, T. Akashi, S. Ishizawa, and H. Fuse, "Urachal signet ring cell carcinoma," International Journal of Urology, vol. 14, no. 4, pp. 360-361, 2007.

[153] M. Morozumi, T. Kawamura, M. Fujime et al., "Urachal carcinoma accompanied with calcification: report of a case," Hinyokika Kiyo, vol. 34, no. 9, pp. 1657-1660, 1988.

[154] A. C. Morson, "Carcinoma of the bladder arising in the urachus," Proceeding of the Royal Society of Medicine, vol. 23, p. 332, 1930.

[155] M. Munichor, S. Szvalb, H. Cohen, and W. Bitterman, "Mixed adenocarcinoma and neuroendocrine carcinoma arising in the urachus," European Urology, vol. 28, no. 4, pp. 345-347, 1995.

[156] K. Nakamura, N. Terada, Y. Shimizu et al., "Pseudomyxoma peritonei arising from urachal carcinoma," Hinyokika Kiyo, vol. 59, no. 10, pp. 657-662, 2013.

[157] K. Nakanishi, T. Kawai, M. Suzuki, and C. Torikata, "Prognostic factors in urachal adenocarcinoma. A study in 41 specimens of DNA status, proliferating cell-nuclear antigen immunostaining, and argyrophilic nucleolar-organizer region counts," Human Pathology, vol. 27, no. 3, pp. 240-247, 1996.

[158] J. A. Nesbitt and P. J. Walther, "Computed tomographic imaging of microscopic dystrophic calcification in urachal adenocarcinoma," Urology, vol. 27, no. 2, pp. 184-186, 1986.

[159] T. Neumark, N. Juul, S. Torp-Pedersen, and J. Kjaergaard, "Ultrasound diagnosis of carcinoma of the urachus," Scandinavian Journal of Urology and Nephrology, vol. 19, no. 1, pp. 71-72, 1985.

[160] A. Nimmonrat, W. Na-Chiang Mai, and M. Muttarak, "Urachal abnormalities: clinical and imaging features," Singapore Medical Journal, vol. 49, no. 11, pp. 930-935, 2008.

[161] H. T. Niu, P. Dong, J. N. Wang, J. Huang, and Y. X. Zeng, "Analysis of treatment and prognosis in post-operative patients with urachal carcinoma," Zhonghua Yi Xue Za Zhi, vol. 96, no. 24, pp. 1923-1925, 2016.

[162] M. Oberndoerfer, P. Bucher, A. Caviezel et al., "Laparoscopic treatment of mucinous urachal adenocarcinoma with mucocele," Surgical Laparoscopy, Endoscopy \& Percutaneous Techniques, vol. 19, no. 1, pp. e26-e28, 2009.

[163] S. Ohira, S. Shiohara, K. Itoh, T. Ashida, M. Fukushima, and I. Konishi, "Urachal adenocarcinoma metastatic to the ovaries: case report and literature review," International Journal of Gynecological Pathology, vol. 22, no. 2, pp. 189193, 2003. 
[164] A. Ojea Calvo, A. Nunez Lopez, F. Dominguez Freire et al., "Mucinous adenocarcinoma of the urachus," Actas Urológicas Españolas, vol. 27, no. 2, pp. 142-146, 2003.

[165] K. Okamoto, T. Fukuyama, E. Okamoto, O. Yoshida, and H. Hiai, "Adenocarcinoma of the urachus associated with stromal osseous metaplasia," Urologia Internationalis, vol. 51, no. 4, pp. 240-242, 1993.

[166] T. Okubo, M. Kawada, D. Saikawa et al., "Surgical treatment for refractory metastatic lung tumors from urachal carcinoma after chemotherapy," Kyobu Geka, vol. 69, no. 3, pp. 210-213, 2016.

[167] S. Okumura, T. Nishimura, J. Hasegawa, S. Kanamori, H. Abe, and M. Akimoto, "Carcinoma of urachus: report of 3 cases and review of literature," Hinyokika Kiyo, vol. 30, no. 9, pp. 1255-1261, 1984.

[168] M. O'Leary and M. Foley, "A case of urachal carcinoma," Journal of Obstetrics and Gynaecology, vol. 24, no. 3, pp. 332-333, 2004.

[169] T. Ormeci, M. C. Kiremit, B. Erkurt, and A. Ormeci, "An unusual long-term survey of a patient with widespread malignant urachal tumor, not given chemotherapy or radiotherapy," Case Reports in Radiology, vol. 2015, Article ID 183787, 4 pages, 2015.

[170] T. G. Orr Jr and C. A. Hardin, "Mucinous adenocarcinoma of the urachus," The American Surgeon, vol. 19, no. 5, pp. 458462, 1953.

[171] O. Oyar, A. Yesildag, U. K. Gulsoy, and H. Perk, "The image of urachus adenocarcinoma on Doppler ultrasonography," European Journal of Radiology, vol. 44, no. 1, pp. 48-51, 2002.

[172] A. J. Pantuck, E. Bancila, K. M. Das et al., "Adenocarcinoma of the urachus and bladder expresses a unique colonic epithelial epitope: an immunohistochemical study," The Journal of Urology, vol. 158, no. 5, pp. 1722-1727, 1997.

[173] B. Parikh, P. Trivedi, A. Ohri, K. Shukla, and S. Desai, "Primary mucinous carcinoma of urachus-a case report," Indian Journal of Pathology \& Microbiology, vol. 49, no. 3, pp. 409-411, 2006.

[174] G. Ogaya Pinies, F. Herranz Amo, G. Escribano Patino et al., "Urachal adenocarcinoma. Case report and bibliographic review," Archivos Espanoles de Urologia, vol. 65, no. 4, pp. 498-501, 2012.

[175] J. Y. Park, T. J. Jeon, M. J. Ryu, and W. C. Shin, "Urachal cancer with direct caecal invasion: differential diagnosis from primary colon cancer," BMJ Case Reports, vol. 2014, 2014.

[176] M. Parker, "Urachal carcinoma: two case reports and a review of the literature," British Journal of Surgery, vol. 70, no. 4, pp. 240-241, 1983.

[177] R. M. Peterson, C. Ollayos, and D. Merchant, "Urachal adenocarcinoma: incidental finding at the time of surgery for ruptured appendicitis," Journal of the Society of Laparoendoscopic Surgeons, vol. 10, no. 3, pp. 392-395, 2006.

[178] A. V. Pollock, "A case of adenocarcinoma of the urachus showing extensive calcification," British Journal of Surgery, vol. 40, no. 160, pp. 187-188, 1952.

[179] F. Porpiglia, C. M. Cracco, C. Terrone et al., "Combined endoscopic and laparoscopic en bloc resection of the urachus and the bladder dome in a rare case of urachal carcinoma," International Journal of Urology, vol. 14, no. 4, pp. 362-364, 2007.

[180] M. R. Prakash, S. V. Vijayalaxmi, R. Maitreyee, and K. P. Ranjit, "Complex mucinous cystadenoma of undetermined malignant potential of the urachus: a rare case with review of the literature," Malaysian Journal of Pathology, vol. 36, pp. 145-148, 2014.

[181] R. J. Prentiss, R. B. Mullenix, J. M. Whisenand, and M. J. Feeney, "Tumors of the urachus-report of five cases," California Medicine, vol. 84, no. 1, pp. 24-28, 1956.

[182] M. Prober and J. H. McBeath, "Mucinous urachal adenocarcinoma. A case report and a review of the literature," Manitoba Medical Review, vol. 49, no. 6, pp. 179-181, 1969.

[183] R. Ravi, "Signet-ring cell carcinoma of urachus: a case report and review of literature," Archivos Espanoles de Urologia, vol. 43, no. 8, pp. 927-929, 1990.

[184] R. Ravi, B. R. Shrivastava, G. M. Chandrasekhar, S. Prahlad, K. V. Balasubramanian, and V. S. Mallikarjuna, "Adenocarcinoma of the urachus," Journal of Surgical Oncology, vol. 50, no. 3, pp. 201-203, 1992.

[185] C. Reek, M. Graefen, A. Erbersdobler, and A. Haese, "Mucinous adenocarcinoma of the urachus. Case report and review of the literature," Urologe A, vol. 39, no. 6, pp. 572-575, 2000.

[186] T. Ribalta, R. L. Shannon, J. Y. Ro, C. H. Carrasco, and A. G. Ayala, "Case report 645: metastatic mucin-producing adenocarcinoma consistent with urachal origin," Skeletal Radiology, vol. 19, no. 8, pp. 616-619, 1990.

[187] A. E. Romero-Rojas, O. A. Messa-Botero, M. A. Melo-Uribe, J. A. Diaz-Perez, and S. I. Chinchilla-Olaya, "Primary yolk sac tumor of the urachus," International Journal of Surgical Pathology, vol. 19, no. 5, pp. 658-661, 2011.

[188] L. Rosen, W. K. Hoddick, H. Hricak, and T. F. Lue, "Urachal carcinoma," Urologic Radiology, vol. 7, no. 1, pp. 174-177, 1985.

[189] D. Rubell and R. F. Porges, "Carcinoma of the urachus. A case report and review," Obstetrics \& Gynecology, vol. 39, no. 5, pp. 753-755, 1972.

[190] K. Sakamoto, H. Tokita, K. Koseki et al., "A case of urachal carcinoma with transverse colon fistula," Gan to Kagaku Ryoho, vol. 36, no. 12, pp. 2269-2271, 2009.

[191] A. S. Salinas Sánchez, C. Alcala-Santaella Casanova, M. Martinez Martin, J. M. Pastor Guzman, L. Canamares Pabolaza, and J. Virseda Rodriguez, "Adenocarcinomas of the urachus," Archivos Espanoles de Urologia, vol. 44, no. 1, pp. 31-36, 1991.

[192] R. A. Santucci, L. D. True, and P. H. Lange, "Is partial cystectomy the treatment of choice for mucinous adenocarcinoma of the urachus?," Urology, vol. 49, no. 4, pp. 536-540, 1997.

[193] R. C. Sarno, G. Klauber, and B. L. Carter, "Computer assisted tomography of urachal abnormalities," Journal of Computer Assisted Tomography, vol. 7, no. 4, pp. 674-676, 1983.

[194] T. Satake and M. Matsuyama, "Neoplastic nature of argyrophil cells in urachal adenocarcinoma," Pathology International, vol. 36, no. 10, pp. 1587-1592, 1986.

[195] W. R. Schaffarzick, "Mucinous adenocarcinoma of the urachus; report of a case," The American Surgeon, vol. 20, no. 8, pp. 887-892, 1954.

[196] S. Scabini, E. Rimini, E. Romairone et al., "Urachal tumour: case report of a poorly understood carcinoma," World Journal of Surgical Oncology, vol. 7, no. 1, p. 82, 2009.

[197] J. Schnur, S. Nguyen, C. Divino, T. Heimann, and C. Vidal, "Coexisting rectal and urachal carcinoma: a case report," American Journal of Clinical Oncology, vol. 32, no. 2, pp. 220-221, 2009. 
[198] J. L. Seibel, S. Prasad, R. E. Weiss, E. Bancila, and J. I. Epstein, "Villous adenoma of the urinary tract: a lesion frequently associated with malignancy," Human Pathology, vol. 33, no. 2, pp. 236-241, 2002.

[199] H. Sekine, K. Ohya, S. Kojima, and K. Mizuguchi, "Dermatomyositis associated with urachal adenocarcinoma," The Journal of Urology, vol. 168, no. 4, pp. 1488-1489, 2002.

[200] N. Sekita, M. Fujimura, H. Arai et al., "A case of urachal carcinoma treated with S-1/CDDP combination chemotherapy," Hinyokika Kiyo, vol. 56, no. 8, pp. 447-451, 2010.

[201] G. J. Shao, L. Cai, X. S. Li et al., "Urachal carcinoma: experience of a clinical center within 30 years," Beijing Da Xue Xue Bao. Yi Xue Ban, vol. 45, no. 5, pp. 774-778, 2013.

[202] T. Shimoyama, N. Horie, T. Yamada, and F. Ide, "Parotid lymph node metastasis from adenocarcinoma of the urachus," Dentomaxillofacial Radiology, vol. 29, no. 3, pp. 185$188,2000$.

[203] T. Shishido, I. Miura, K. Watanabe et al., "Urachal anomalies and tumor: clinical investigation of 14 cases," Hinyokika Kiyo, vol. 51, no. 11, pp. 731-735, 2005.

[204] H. Singh, Y. Liu, X. Xiao et al., "Whole exome sequencing of urachal adenocarcinoma reveals recurrent NF1 mutations," Oncotarget, vol. 7, no. 20, pp. 29211-29215, 2016.

[205] G. S. Slater and G. L. Torassa, "Mucinous adenocarcinoma of urachus connected to urinary bladder," Stanford Medical Bulletin, vol. 11, no. 1, pp. 19-29, 1953.

[206] P. E. Spiess and J. J. Correa, "Robotic assisted laparoscopic partial cystectomy and urachal resection for urachal adenocarcinoma," International Brazilian Journal of Urology, vol. 35, no. 5, p. 609, 2009.

[207] P. H. Sugarbaker, M. Verghese, T. D. Yan, and E. Brun, "Management of mucinous urachal neoplasm presenting as pseudomyxoma peritonei," Tumori Journal, vol. 94, no. 5, pp. 732-736, 2008.

[208] K. Sugiyama and N. Ito, "Mucinous cystadenocarcinoma of the urachus associated with pseudomyxoma peritonei with emphasis on MR findings," Magnetic Resonance in Medical Sciences, vol. 8, no. 2, pp. 85-89, 2009.

[209] J. F. Sullivan, D. M. Fanning, I. Cheema, and T. Creagh, "A rare case of recurrent urachal adenocarcinoma of the bladder," Irish Medical Journal, vol. 106, no. 5, pp. 147148, 2013.

[210] H. Suzuki, K. Yamada, G. Kimura et al., "A case of signet ring cell carcinoma of the urachus," Hinyokika Kiyo, vol. 37, no. 6, pp. 633-635, 1991.

[211] K. Suzuki and R. Watanabe, "Early urachal carcinoma diagnosed by magnetic resonance imaging: a case report," Hinyokika Kiyo, vol. 43, no. 1, pp. 57-59, 1997.

[212] H. C. Tai, Y. S. Chen, S. M. Wang, S. C. Chueh, M. K. Lai, and H. J. Yu, "Urachal adenocarcinoma following kidney transplantation: the first case report," Transplantation Proceedings, vol. 41, no. 5, pp. 1939-1941, 2009.

[213] M. Takeuchi, K. Matsuzaki, S. Yoshida, H. Nishitani, and H. Uehara, "Imaging findings of urachal mucinous cystadenocarcinoma associated with pseudomyxoma peritonei," Acta Radiologica, vol. 45, no. 3, pp. 348-350, 2004.

[214] M. Tatokoro, S. Kawakami, J. Yonese et al., "Preliminary report of multimodal treatment with ifosfamide, 5-fluorouracil, etoposide and cisplatin (IFEP chemotherapy) against metastatic adenocarcinoma of the urachus," International Journal of Urology, vol. 15, no. 9, pp. 851-853, 2008.
[215] M. Tatsuno, S. Tamura, F. Taniguchi, H. Yasuoka, H. Nasu, and T. Fujimoto, "A case of metastatic pulmonary cancer from urachal carcinoma that required differentiation from primary lung adenocarcinoma," Nihon Kokyūki Gakkai Zasshi, vol. 49, no. 11, pp. 848-854, 2011.

[216] D. Taussky, P. I. Karakiewicz, M. Latour, and N. Blais, "Brain metastasis from urachal carcinoma: the importance of locally aggressive treatment," Rare Tumors, vol. 4, article e17, 2012.

[217] S. Taylor, P. Bacchini, and F. Bertoni, "An isolated vertebral metastasis of urachal adenocarcinoma," Archives of Pathology \& Laboratory Medicine, vol. 128, no. 9, pp. 1043-1045, 2004

[218] M. K. Tewari, V. K. Khosla, B. S. Sharma, R. K. Vashistha, N. K. Khandelwal, and V. K. Kak, "Brain metastasis from urachal carcinoma: case report," Surgical Neurology, vol. 42, no. 4, pp. 340-342, 1994.

[219] C. M. Thali-Schwab, P. J. Woodward, and B. J. Wagner, "Computed tomographic appearance of urachal adenocarcinomas: review of 25 cases," European Radiology, vol. 15, no. 1, pp. 79-84, 2005.

[220] B. Thirunavukkarasu, A. R. Mridha, S. Yadav, R. Kumar, and S. Gamanagatti, "Fine needle aspiration cytology diagnosis of an urachal adenocarcinoma," Journal of Clinical and Diagnostic Research, vol. 10, no. 4, pp. ED10-ED12, 2016.

[221] A. A. Thomas, A. J. Stephenson, S. C. Campbell, J. S. Jones, and D. E. Hansel, "Clinicopathologic features and utility of immunohistochemical markers in signet-ring cell adenocarcinoma of the bladder," Human Pathology, vol. 40, no. 1, pp. 108-116, 2009.

[222] A. J. Thomas, M. S. Pollack, and H. I. Libshitz, "Urachal carcinoma: evaluation with computed tomography," Urologic Radiology, vol. 8, no. 1, pp. 194-198, 1986.

[223] J. Tian, J. H. Ma, C. L. Li, and Z. D. Xiao, "Urachal mass in adults: clinical analysis of 33 cases," Zhonghua Yi Xue Za Zhi, vol. 88, no. 12, pp. 820-822, 2008.

[224] K. Tokinaga, K. Inoue, I. Yamasaki et al., "Microscopic foci of urachal carcinoma in an incidentally detected urachal cyst: a case report," Hinyokika Kiyo, vol. 43, no. 10, pp. 731-733, 1997.

[225] K. Tomita, K. I. Tobisu, H. Kume, H. Fujimoto, and T. Kakizoe, "Long survival with extended surgery for urachal carcinoma involving adjacent organs," Journal of Urology, vol. 159, no. 4, p. 1298, 1998.

[226] C. Trastour, B. Desprez, J. Delotte et al., "Ovarian metastases from an urachal adenocarcinoma," European Journal of Obstetrics \& Gynecology, vol. 125, no. 1, pp. 143-144, 2006.

[227] A. Tsiouris, H. U. Ahmed, N. Kumar, and A. V. Kaisary, "Urachal tumour: clinical and radiological features of a poorly understood carcinoma," Annals of the Royal College of Surgeons of England, vol. 89, no. 6, pp. W17-W18, 2007.

[228] H. Uemura, Y. Kinoshita, Y. Kubota, T. Shuin, and M. Hosaka, "Use of polypropylene mesh for abdominal wall defect in surgery of advanced urachus carcinoma," Urologia Internationalis, vol. 43, no. 2, pp. 102-103, 1988.

[229] K. Van Calsteren, K. Van Mensel, S. Joniau et al., "Urachal carcinoma during pregnancy," Urology, vol. 67, pp. 1290.e191290.e21, 2006.

[230] P. Wadhwa, S. B. Kolla, and A. K. Hemal, "Laparoscopic en bloc partial cystectomy with bilateral pelvic lymphadenectomy for urachal adenocarcinoma," Urology, vol. 67, no. 4, pp. 837-843, 2006. 
[231] B. Wang, X. Li, S. Ming et al., "Combined extraperitoneal and transperitoneal laparoscopic extended partial cystectomy for the treatment of urachal carcinoma," Journal of Endourology, vol. 30, no. 3, pp. 280-285, 2016.

[232] Y. Watanabe, S. Itoh, and N. Mitsuhata, "Urachal carcinoma treated with neoadjuvant intra-arterial chemotherapy: a case report," Hinyokika Kiyo, vol. 50, no. 10, pp. 713-716, 2004.

[233] M. Wells and K. Anderson, "Mucin histochemistry of cystitis glandularis and primary adenocarcinoma of the urinary bladder," Archives of Pathology \& Laboratory Medicine, vol. 109, no. 1, pp. 59-61, 1985.

[234] M. S. Wessell, A. B. Kuritz, R. A. Burger, and G. W. Reagan, "Mucinous carcinoma of the urachus invading the bladder," The Journal of Urology, vol. 67, no. 4, pp. 523-525, 1952.

[235] C. R. Williams and K. Chavda, "En bloc robot-assisted laparoscopic partial cystectomy, urachal resection, and pelvic lymphadenectomy for urachal adenocarcinoma," Reviews Urology, vol. 17, pp. 46-49, 2015.

[236] K. I. Wishnow, "Endovesical ultrasonography of urachal carcinoma," Urologic Radiology, vol. 11, no. 1, pp. 53-54, 1989.

[237] A. Witeska and S. Dutkiewicz, "A rare case of adenocarcinoma of the urachus," International Urology and Nephrology, vol. 26, no. 3, pp. 323-326, 1994.

[238] J. J. Wong-You-Cheong, T. L. Krebs, B. Daly, and K. Grumbach, "General case of the day. Adenocarcinoma of the urachus," Radiographics, vol. 18, no. 6, pp. 1614-1616, 1998.

[239] T. Yamada, I. Fukui, H. Sekine, K. Kihara, and H. Oshima, "Treatment methods as a prognostic factor in eight patients with urachal carcinoma," Hinyokika Kiyo, vol. 37, no. 2, pp. 113-116, 1991.

[240] T. D. Yan, P. H. Sugarbaker, and E. A. Brun, "Pseudomyxoma peritonei from mucinous adenocarcinoma of the urachus," Journal of Clinical Oncology, vol. 24, no. 30, pp. 4944-4946, 2006.

[241] Y. Yanagihara, N. Tanji, N. Miura et al., "Modified FOLFOX6 chemotherapy in patients with metastatic urachal cancer," Chemotherapy, vol. 59, no. 6, pp. 402-406, 2013.

[242] S. Yanagisawa, Y. Fujinaga, and M. Kadoya, "Urachal mucinous cystadenocarcinoma with a cystic ovarian metastasis," American Journal of Roentgenology, vol. 180, no. 4, pp. 1183-1184, 2003.

[243] T. Yasui, T. Okamura, H. Akita, M. Kojima, and K. Kohri, "Urethral recurrence of an urachal carcinoma: a case report," International Journal of Urology, vol. 4, no. 1, pp. 106-108, 1997.

[244] S. Yazawa, E. Kikuchi, T. Takeda et al., "Surgical and chemotherapeutic options for urachal carcinoma: report of ten cases and literature review," Urologia Internationalis, vol. 88, no. 2, pp. 209-214, 2012.

[245] W. Yin, X. L. Mo, Z. H. Wen, X. Z. Zhou, M. Y. Zhou, and H. M. Wei, "Villous adenoma of the urinary tract: a clinicopathological study," Zhonghua Bing Li Xue Za Zhi, vol. 42, no. 7, pp. 438-441, 2013.

[246] Y. Yoshida, K. Yamanaka, N. Ueda et al., "A case of urachal carcinoma with multiple lung metastases treated by TS-1/ CDDP chemotherapy," Hinyokika Kiyo, vol. 60, no. 3, pp. 147-150, 2014.

[247] R. H. Young, "Urachal adenocarcinoma metastatic to the ovary simulating primary mucinous cystadenocarcinoma of the ovary: report of a case," Virchows Archiv, vol. 426, no. 5, pp. 529-532, 1995.

[248] B. Yu, J. Zhou, H. Cai et al., "Neoadjuvant chemotherapy for primary adenocarcinomas of the urinary bladder: a single-site experience," BMC Urology, vol. 15, no. 1, p. 3, 2015.

[249] R. J. Zagoria, W. J. Higgins, G. T. King, and C. D. Williams, "Elderly man with hematuria and a pelvic mass. Mucinous adenocarcinoma of the urachus," Investigative Radiology, vol. 22, no. 5, pp. 424-426, 1987.

[250] H. Zhang, H. Jiang, Z. Wu, Z. Fang, J. Fan, and Q. Ding, "Primary adenocarcinoma of the urinary bladder: a single site analysis of 21 cases," International Urology and Nephrology, vol. 45, no. 1, pp. 107-111, 2013.

[251] L. Zong and P. Chen, "Surgical and chemotherapeutic experience regarding a urachal carcinoma with repeated relapse: case report and literature review," World Journal of Surgical Oncology, vol. 11, no. 1, p. 170, 2013.

[252] A. Ayala and P. Tamboli, "Urachal carcinoma," in World Health Organization Classification of Tumours: Pathology and Genetics of Tumours of the Urinary System and Male Genital Organs, J. Eble, G. Sauter, J. I. Epstein, and I. A. Sesterhenn, Eds., pp. 131-132, IARC, Lyon, France, 2004.

[253] A. Lopez-Beltran, G. Paner, and T. Tsuzuki, "Urachal carcinoma," in World Health Organization Classification of Tumours of the Urinary System and Male Genital Organs, H. Moch, P. A. Humphrey, T. M. Ulbright, and V. E. Reuter, Eds., pp. 113-114, IARC, Lyon, France, 2016.

[254] M. A. Behrendt, J. De Jong, and B. W. Van Rhijn, "Urachal cancer: contemporary review of the pathological, surgical, and prognostic aspects of this rare disease," Minerva Urologica e Nefrologica, vol. 68, no. 2, pp. 172-184, 2016.

[255] N. Nese, G. Kesici, M. Lekili, and A. Isisag, "Urachal urothelial carcinoma diagnosed at a radical prostatectomy operation: a case report," Analytical and Quantitative Cytology and Histology, vol. 32, no. 3, pp. 174-177, 2010.

[256] G. L. Pedersen, C. Dahl, and N. H. Azawi, "Non-invasive, low-grade papillary urothelial carcinoma in the urachus," BMJ Case Reports, vol. 2013, 2013.

[257] V. Maletic, S. Cerovic, M. Lazic, M. Stojanovic, and P. Stevanovic, "Synchronous and multiple transitional cell carcinoma of the bladder and urachal cyst," International Journal of Urology, vol. 15, no. 6, pp. 554-556, 2008.

[258] C. Lara, V. Porras, P. Jurado, A. Gomez, and F. Arredondo, "Papillary urothelial carcinoma of the urachus," Archivos Espanoles de Urologia, vol. 59, no. 9, pp. 914-916, 2006.

[259] P. A. Isotalo, S. J. Robertson, and N. G. Futter, "Urinary bladder urachal remnants underlying papillary urothelial carcinoma," Archives of Pathology \& Laboratory Medicine, vol. 126, no. 10, pp. 1252-1253, 2002.

[260] K. Abe, T. Wada, M. Ueda, and Y. Ohishi, "Transitional cell carcinoma of urachus: a case report," Hinyokika Kiyo, vol. 46, no. 9, pp. 631-634, 2000.

[261] J. P. Rubin, J. M. Kasznica, C. A. Davis, G. A. C. 3rd, and E. F. Hirsch, "Transitional cell carcinoma in a urachal cyst," The Journal of Urology, vol. 162, no. 5, pp. 16871688, 1999.

[262] O. Ichiyanagi, I. Sasagawa, Y. Suzuki et al., "Successful chemotherapy in a patient with recurrent carcinoma of the urachus," International Urology and Nephrology, vol. 30, no. 5, pp. 569-573, 1998. 
[263] I. Satake, K. Nakagomi, K. Tari, and K. Kishi, "Metachronous transitional cell carcinoma of the urachus and bladder," British Journal of Urology, vol. 75, no. 2, p. 244, 1995.

[264] D. R. Lyth and C. M. Booth, "Transitional cell carcinoma of the urachus," British Journal of Urology, vol. 65, no. 5, pp. 544-545, 1990.

[265] K. Saito, A. Furuhata, K. Ogawa, and H. Nakagome, "Urachal transitional cell carcinoma invading the sigmoid colon," Hinyokika Kiyo, vol. 34, no. 6, pp. 1039-1042, 1988.

[266] Y. Kidera, Y. Uchiyama, T. Iwasaka, Y. Ohkuma, T. Yoshimura, and H. Sugimori, "A case of urachal carcinoma with Meigs's syndrome," Journal of Obstetrics and Gynaecology Research, vol. 12, no. 1, pp. 57-61, 1986.

[267] E. R. Fisher, "Transitional-cell carcinoma of the urachal apex," Cancer, vol. 11, no. 2, pp. 245-249, 1958.

[268] A. Cheikhelard, S. Irtan, D. Orbach et al., "Urachal rhabdomyosarcoma in childhood: a rare entity with a poor outcome," Journal of Pediatric Surgery, vol. 50, no. 8, pp. 1329-1333, 2015.

[269] E. M. López-Tomassetti Fernández, N. H. Siverio, R. L. Almaraz, L. M. Viota, J. R. Luis, and L. D. Flores, "Radical surgery and IVA-chemotherapeutic regimen to treat embryonal rhabdomyosarcoma of the urachus: case report," Pediatric Hematology and Oncology, vol. 24, no. 7, pp. 543-550, 2007.

[270] U. Schulz and C. P. O'Leary, "Spinal AVM, epidermal nevus, and rhabdomyosarcoma: a rare neurocutaneous syndrome?," Neurology, vol. 56, no. 3, pp. 395-397, 2001.

[271] S. Yokoyama, Y. Hayashida, J. Nagahama et al., "Rhabdomyosarcoma of the urachus. A case report," Acta Cytologica, vol. 41, no. s1, pp. 1293-1298, 1997.

[272] C. H. Whittle, E. Coryllos, and J. S. Simpson Jr, "Sarcoma of the urachus," JAMA Surgery, vol. 82, no. 3, pp. 443-444, 1961.

[273] A. Saied, S. Salzman, S. N. Hochwald, and J. G. Trevino, "Traumatic intraperitoneal rupture of an urachal leiomyosarcoma: unique presentation as hemorrhagic shock," The American Surgeon, vol. 78, no. 9, pp. E409-E411, 2012.

[274] S. O. Kim, D. Kwon, C. Choi, H. J. Baek, K. Park, and S. B. Ryu, "A case of spontaneous rupture perforation of leiomyosarcoma in the urachus of a young boy," International Journal of Urology, vol. 14, no. 10, pp. 960-962, 2007.

[275] K. Kato, K. Arai, Y. Tanaka et al., "Epithelioid leiomyosarcoma in a non-immunocompromised infant: additional differential diagnosis of pediatric "round cell tumors"," Modern Pathology, vol. 13, no. 10, pp. 1156-1160, 2000.

[276] D. Noyes and R. K. Vinson, "Urachal leiomyosarcoma," Urology, vol. 17, no. 3, pp. 279-280, 1981.

[277] S. Lacquaniti, P. P. Fasolo, E. Conti, G. Sebastiani, and G. Fasolis, "Inflammatory fibrosarcoma of the urachus: a case report," Archivio Italiano di Urologia, Andrologia, vol. 75, pp. 226-227, 2003.

[278] J. N. Bruneton, J. Drouillard, A. Rogopoulos et al., "Extraretroperitoneal abdominal malignant fibrous histiocytoma," Gastrointestinal Radiology, vol. 13, no. 1, pp. 299-305, 1988.

[279] P. H. Powley, "Sarcoma of the urachus," British Journal of Surgery, vol. 48, no. 212, pp. 649-650, 1961.

[280] D. B. Butler and H. S. Rosenberg, "Sarcoma of the urachus," Archives of Surgery, vol. 79, no. 5, pp. 724-728, 1959.

[281] R. E. Shaw, "Sarcoma of the urachus; report of a case and brief review of the subject," British Journal of Surgery, vol. 37, no. 145 , pp. 95-98, 1949.
[282] L. McNally, S. Osmundson, R. Barth, and J. Chueh, "Urachal duct carcinoma complicating pregnancy," Obstetrics \& Gynecology, vol. 122, no. 2, Part 2, pp. 469-472, 2013.

[283] S. Andrei, A. Andrei, G. Rusu Muntean et al., "A rare case of metastatic squamous urachal carcinoma," Chirurgia, vol. 108, no. 2, pp. 280-284, 2013.

[284] M. Kikuchi, S. Kamei, Y. Morirama et al., "Case of urachal cancer treated by neoadjuvant chemotherapy with FOLFOX4 (oxaliplatin, 5-FU and leukovolin)," Hinyokika Kiyo, vol. 54, no. 8, pp. 557-559, 2008.

[285] T. Kuramoto, K. Kikkawa, M. Nishihata et al., "Squamous cell carcinoma of the urachus producing granulocyte colonystimulating factor," Urology, vol. 73 , no. 2, pp. 442.e5442.e7, 2009.

[286] C. Fujiyama, N. Nakashima, Y. Tokuda, and J. Uozumi, "Squamous cell carcinoma of the urachus," International Journal of Urology, vol. 14, no. 10, pp. 966-968, 2007.

[287] Y. C. Chow, W. C. Lin, C. Y. Tzen, Y. K. Chow, and K. Y. Lo, "Squamous cell carcinoma of the urachus," The Journal of Urology, vol. 163, no. 3, pp. 903-904, 2000.

[288] A. Jimi, H. Munaoka, S. Sato, and Y. Iwata, "Squamous cell carcinoma of the urachus. A case report and review of literature," Pathology International, vol. 36, no. 6, pp. 945-952, 1986.

[289] R. Y. Lin, A. E. Rappoport, L. M. Deppisch, N. S. Natividad, and W. Katz, "Squamous cell carcinoma of the urachus," The Journal of Urology, vol. 118, no. 6, pp. 1066-1067, 1977.

[290] B. D. Pujari, M. Phansopkar, and S. G. Deodhare, "Squamous cell carcinoma of the urachus with vesical calculus," British Journal of Urology, vol. 49, no. 4, p. 292, 1977.

[291] R. E. Shaw, "Squamous-cell carcinoma in a cyst of the urachus," British Journal of Urology, vol. 30, no. 1, pp. 87-89, 1958.

[292] N. Shaw, D. Marchalik, and L. Stamatakis, "Incidentally discovered urachal cancer in a patient with necrotising fasciitis of the abdominal wall," BMJ Case Reports, vol. 2016, 2016.

[293] F. Tareen, D. T. McDowell, M. O’Sullivan, and A. Mortell, "Urachal carcinoid-a new presentation," European Journal of Pediatric Surgery, vol. 23, no. 3, pp. e1-e2, 2013.

[294] A. D’Alessio, G. Verdelli, M. Bernardi et al., "Endodermal sinus (yolk sac) tumor of the urachus," European Journal of Pediatric Surgery, vol. 4, no. 03, pp. 180-181, 1994.

[295] H. Y. Huang, S. F. Ko, J. H. Chuang, Y. M. Jeng, M. T. Sung, and W. J. Chen, "Primary yolk sac tumor of the urachus," Archives of Pathology \& Laboratory Medicine, vol. 126, pp. 1106-1109, 2002.

[296] P. Clapuyt, C. Saint-Martin, P. De Batselier, B. Brichard, F. X. Wese, and S. Gosseye, "Urachal neuroblastoma: first case report," Pediatric Radiology, vol. 29, no. 5, pp. 320-321, 1999.

[297] K. Venkatesh and H. R. Madhusudhan, "Anaplastic lymphoma kinase positive inflammatory myofibroblastic tumor of the urachus: a rare neoplasm in an unusual location," Indian Journal of Pathology \& Microbiology, vol. 59, no. 1, pp. 93-95, 2016.

[298] A. F. Nascimento, P. Dal Cin, B. G. Cilento, A. R. PerezAtayde, H. P. W. Kozakewich, and V. Nosé, "Urachal inflammatory myofibroblastic tumor with ALK gene rearrangement: a study of urachal remnants," Urology, vol. 64, no. 1, pp. 140144, 2004. 
[299] M. Kaskas, P. Helfrich, A. Dabrowski, and R. P. Buffin, "Inflammatory pseudotumor of the urachus. A case," Presse Médicale, vol. 21, pp. 1374-1376, 1992.

[300] F. Tunca, O. Sanli, K. Demirkol, and M. Gulluoglu, "Inflammatory pseudotumor of urachus mimicking invasive carcinoma of bladder," Urology, vol. 67, pp. 623.e1-623.e3, 2006.

[301] H. Mizusawa, T. Oguchi, T. Domen et al., "Two cases of lower abdominal tumors difficult to differentiate from urachal tumors," Nihon Hinyokika Gakkai Zasshi, vol. 105, no. 1, pp. 17-21, 2014.

[302] M. Sugi, "A case of abdominal desmoid tumor that was difficult to differentiate from urachal tumor," Hinyokika Kiyo, vol. 50, no. 7, pp. 489-492, 2004.

[303] H. Iuchi, S. Kaneko, S. Tokunaka et al., "Pelvic fibromatosis simulating urachal tumor-a case report," Nihon Hinyokika Gakkai Zasshi, vol. 84, no. 2, pp. 386-389, 1993.

[304] C. M. Baglio and C. N. Crowson, "Hemangiopericytoma of urachus: report of a case," The Journal of Urology, vol. 91, no. 6, pp. 660-662, 1964.

[305] U. Rudloff, A. Jacobson, N. Morgenstern, Y. Chen, and B. R. Lee, "Castleman's disease of the urachus," Urology, vol. 64, no. 2, pp. 376-379, 2004.

[306] N. Agbreta, A. Boutens, and P. Debodinance, "Dermoid cyst of the urachus: a case report and review of the literature," Journal de Gynécologie Obstétrique et Biologie de la Reproduction, vol. 35, no. 1, pp. 75-78, 2006.

[307] U. Cionfoli, C. Malaspina, P. Ciceri et al., "A case of teratoma of the urachus," Minerva Chirurgica, vol. 46, no. 9, pp. 471477, 1991.

[308] N. Defabiani, C. E. Iselin, H. G. Khan, J. C. Pache, and S. Rohner, "Benign teratoma of the urachus," British Journal of Urology, vol. 81, no. 5, pp. 760-761, 1998.

[309] D. C. Ding, M. H. Yu, C. C. Wu, and J. Y. Liu, "Urachal myoma: a case report," Acta Obstetricia et Gynecologica Scandinavica, vol. 82, no. 5, pp. 481-483, 2003.

[310] D. Ramazan, U. Orhan, K. Bulent, O. Nagehan, and T. Cem, "A urachal leiomyoma misdiagnosed as an ovarian tumor," European Journal of Obstetrics \& Gynecology, vol. 100, no. 1, pp. 94-95, 2001.

[311] D. Panero and T. Marzano, "Fibrous hamartoma of the urachus. Report of a case complicated by strangulation of the stalk," Minerva Chirurgica, vol. 53, no. 12, pp. 1047-1049, 1998.

[312] C. Park, H. Kim, Y. B. Lee, J. M. Song, and J. Y. Ro, "Hamartoma of the urachal remnant," Archives of Pathology \& Laboratory Medicin, vol. 113, no. 12, pp. 1393-1395, 1989.

[313] M. I. Ukhal and S. A. Il'iashenko, "Hemangioma of the urachus," Urologiia i Nefrologiia, no. 3, pp. 45-47, 1993.

[314] S. Loening and J. R. Richardson Jr, "Fibroadenoma of the urachus," The Journal of Urology, vol. 112, no. 6, pp. 759-761, 1974.

[315] O. Inci, E. Tastekin, H. Genchellac, O. Arabaci, S. Isler, and I. H. Atakan, "A case of urachal malacoplakia that seems like urachal cancer," Balkan Medical Journal, vol. 32, no. 1, pp. 114-117, 2015.

[316] M. F. McConnell, K. T. Bradley, S. L. Weiss, and R. M. Cantor, "Ultrasound evaluation of urachal abscess in a young infant," Pediatric Emergency Care, vol. 31, no. 2, pp. 135137, 2015.

[317] A. Dong, C. Zuo, Y. Wang, J. Lu, and H. Zhu, “Organized urachal abscess mimicking urachal carcinoma on FDG
PET/CT," Clinical Nuclear Medicine, vol. 39, no. 1, pp. 7173, 2014.

[318] F. Tazi, M. Ahsaini, A. Khalouk et al., "Abscess of urachal remnants presenting with acute abdomen: a case series," Journal of Medical Case Reports, vol. 6, no. 1, p. 226, 2012.

[319] T. L. C. Kuo and C. Cheng, "Xanthogranulomatous inflammation of urachus mimicking urachal carcinoma," Urology, vol. 73, no. 2, pp. 443.e13-443.e14, 2009.

[320] T. Jindal, M. R. Kamal, and J. K. Jha, "Tuberculosis of the urachal cyst," The Korean Journal of Internal Medicine, vol. 28, no. 1, pp. 103-105, 2013.

[321] M. F. Li, T. L. Yang, and J. S. Huang, "Imaging findings of primary urachal actinomycosis," Journal of the Chinese Medical Association, vol. 74, no. 1, pp. 44-47, 2011.

[322] M. Bednarek, L. Bolt, Z. Biesiada, W. Habrat, and S. Demczuk, "Actinomycosis in persistent urachus," Przeglad Lekarski, vol. 67, pp. 141-143, 2010.

[323] Y. Yeung, M. C. Cheung, G. S. W. Chan, A. N. Y. Cheung, and P. C. Tam, "Primary actinomycosis mimicking urachal carcinoma," Urology, vol. 58, no. 3, p. 462, 2001.

[324] S. Lambrechts, K. Van Calsteren, A. Capoen et al., "Polypoid endometriosis of the bladder during pregnancy mimicking urachal carcinoma," Ultrasound in Obstetrics \& Gynecology, vol. 38, no. 4, pp. 475-478, 2011.

[325] H. Takao, K. Yamahira, I. Doi, and T. Watanabe, "Perforated colonic diverticulitis mimicking urachal carcinoma: computed tomography and magnetic resonance findings," Clinical Imaging, vol. 29, no. 2, pp. 144-146, 2005.

[326] M. Hatzinger, M. Stastny, K. Wirsam, and M. Sohn, "The unusual case: a foreign body in the urachus," Aktuelle Urologie, vol. 41, no. 05, pp. 320-322, 2010.

[327] M. C. Pasternak, J. D. Black, N. Buza, M. Azodi, and A. Gariepy, "An unexpected mass of the urachus: a case report," American Journal of Obstetrics \& Gynecology, vol. 211, no. 4, pp. e1-e3, 2014.

[328] D. Chahal, M. Martens, and J. Kinahan, "Mucinous cystic tumour of low malignant potential presenting in a patient with prior non-seminatous germ cell tumour," Canadian Urological Association Journal, vol. 9, no. 9-10, pp. 750753, 2015.

[329] S. Roy, M. A. Smith, K. M. Cieply, M. B. Acquafondata, and A. V. Parwani, "Primary bladder adenocarcinoma versus metastatic colorectal adenocarcinoma: a persisting diagnostic challenge," Diagnostic Pathology, vol. 7, no. 1, p. 151, 2012.

[330] R. W. Werling, H. Yaziji, C. E. Bacchi, and A. M. Gown, "CDX2, a highly sensitive and specific marker of adenocarcinomas of intestinal origin: an immunohistochemical survey of 476 primary and metastatic carcinomas," The American Journal of Surgical Pathology, vol. 27, no. 3, pp. 303-310, 2003.

[331] M. R. Raspollini, G. Nesi, G. Baroni, L. R. Girardi, and G. L. Taddei, "Immunohistochemistry in the differential diagnosis between primary and secondary intestinal adenocarcinoma of the urinary bladder," Applied Immunohistochemistry \& Molecular Morphology, vol. 13, no. 4, pp. 358-362, 2005.

[332] C. A. Moskaluk, H. Zhang, S. M. Powell, L. A. Cerilli, G. M. Hampton, and H. F. Frierson Jr, "Cdx2 protein expression in normal and malignant human tissues: an immunohistochemical survey using tissue microarrays," Modern Pathology, vol. 16, no. 9, pp. 913-919, 2003. 
[333] J. A. Ortiz-Rey, I. Anton Badiola, P. San Miguel Fraile, C. Alvarez Alvarez, B. Iglesias Rodriguez, and E. Zungri-Telo, "Expression of CDX2 in urinary bladder and urethra lesions," Actas Urológicas Españolas, vol. 28, no. 2, pp. 101-105, 2004.

[334] M. T. Sung, A. Lopez-Beltran, J. N. Eble et al., "Divergent pathway of intestinal metaplasia and cystitis glandularis of the urinary bladder," Modern Pathology, vol. 19, no. 11, pp. 1395-1401, 2006.

[335] A. Broede, M. Oll, A. Maurer et al., "Differential diagnosis of bladder versus colorectal adenocarcinoma: keratin 7 and GATA3 positivity in nuclear B-catenin-negative glandular tumours defines adenocarcinoma of the bladder," Journal of Clinical Pathology, vol. 69, no. 4, pp. 307-312, 2016.

[336] B. T. MacDonald, K. Tamai, and X. He, "Wnt/ $\beta$-catenin signaling: components, mechanisms, and diseases," Developmental Cell, vol. 17, no. 1, pp. 9-26, 2009.

[337] T. Brabletz, A. Jung, K. Hermann, K. Gunther, W. Hohenberger, and T. Kirchner, "Nuclear overexpression of the oncoprotein $\beta$-catenin in colorectal cancer is localized predominantly at the invasion front," Pathology - Research and Practice, vol. 194, no. 10, pp. 701-704, 1998.

[338] H. L. Wang, D. W. Lu, L. M. Yerian et al., "Immunohistochemical distinction between primary adenocarcinoma of the bladder and secondary colorectal adenocarcinoma," The American Journal of Surgical Pathology, vol. 25, no. 11, pp. 1380-1387, 2001.

[339] T. Oshima, J. Shan, T. Okugawa et al., "Down-regulation of claudin-18 is associated with the proliferative and invasive potential of gastric cancer at the invasive front," PLoS One, vol. 8, no. 9, article e74757, 2013.

[340] A. Shinozaki, J. Shibahara, N. Noda et al., "Claudin-18 in biliary neoplasms. Its significance in the classification of intrahepatic cholangiocarcinoma," Virchows Archiv, vol. 459, no. 1, pp. 73-80, 2011.

[341] M. Matsuda, K. Sentani, T. Noguchi et al., "Immunohistochemical analysis of colorectal cancer with gastric phenotype: claudin-18 is associated with poor prognosis," Pathology International, vol. 60, no. 10, pp. 673-680, 2010.

[342] N. Oue, Y. Mitani, P. P. Aung et al., "Expression and localization of Reg IV in human neoplastic and non-neoplastic tissues: Reg IV expression is associated with intestinal and neuroendocrine differentiation in gastric adenocarcinoma," The Journal of Pathology, vol. 207, no. 2, pp. 185-198, 2005.

[343] N. Suh, X. J. Yang, M. S. Tretiakova, P. A. Humphrey, and H. L. Wang, "Value of CDX2, villin, and $\alpha$-methylacyl coenzyme A racemase immunostains in the distinction between primary adenocarcinoma of the bladder and secondary colorectal adenocarcinoma," Modern Pathology, vol. 18, no. 9, pp. 1217-1222, 2005.

[344] H. H. Wong and P. Chu, "Immunohistochemical features of the gastrointestinal tract tumors," Journal of Gastrointestinal Oncology, vol. 3, no. 3, pp. 262-284, 2012.

[345] A. H. Seipel, H. Samaratunga, B. Delahunt, P. Wiklund, M. Clements, and L. Egevad, "Immunohistochemistry of ductal adenocarcinoma of the prostate and adenocarcinomas of non-prostatic origin: a comparative study," APMIS, vol. 124, no. 4, pp. 263-270, 2016.

[346] M. J. Lee, H. S. Lee, W. H. Kim, Y. Choi, and M. Yang, "Expression of mucins and cytokeratins in primary carcinomas of the digestive system," Modern Pathology, vol. 16, no. 5, pp. 403-410, 2003.
[347] M. D. Walsh, M. Clendenning, E. Williamson et al., "Expression of MUC2, MUC5AC, MUC5B, and MUC6 mucins in colorectal cancers and their association with the CpG island methylator phenotype," Modern Pathology, vol. 26, no. 12, pp. 1642-1656, 2013.

[348] B. R. Kipp, H. L. Tyner, M. B. Campion et al., “Chromosomal alterations detected by fluorescence in situ hybridization in urothelial carcinoma and rarer histologic variants of bladder cancer," American Journal of Clinical Pathology, vol. 130, no. 4, pp. 552-559, 2008.

[349] N. J. Carr and A. D. McLean, "A mucinous tumour of the urachus: adenoma or low grade mucinous cystic tumour of uncertain malignant potential?," Advances in Clinical Pathology, vol. 5, no. 3, pp. 93-97, 2001.

[350] Y. Arai, T. Konami, and T. Tomoyoshi, "Urachal carcinoma producing carcinoembryonic antigen: a case report," Hinyokika Kiyo, vol. 35, no. 6, pp. 1065-1068, 1989.

[351] Y. Hu, J. L. Wang, H. T. Tao et al., "Expression and significance of TSGF, CEA and AFP in patients before and after radical surgery for colon cancer," Asian Pacific Journal of Cancer Prevention, vol. 14, no. 6, pp. 3877-3880, 2013.

[352] R. W. Brown, L. B. Campagna, J. K. Dunn, and P. T. Cagle, "Immunohistochemical identification of tumor markers in metastatic adenocarcinoma. A diagnostic adjunct in the determination of primary site," American Journal of Clinical Pathology, vol. 107, no. 1, pp. 12-19, 1997.

[353] T. Terada, "An immunohistochemical study of primary signet-ring cell carcinoma of the stomach and colorectum: III. Expressions of EMA, CEA, CA19-9, CDX-2, p53, Ki-67 antigen, TTF-1, vimentin, and p63 in normal mucosa and in 42 cases," International Journal of Clinical and Experimental Pathology, vol. 6, no. 4, pp. 630-638, 2013.

[354] Q. Rao, S. R. Williamson, A. Lopez-Beltran et al., "Distinguishing primary adenocarcinoma of the urinary bladder from secondary involvement by colorectal adenocarcinoma: extended immunohistochemical profiles emphasizing novel markers," Modern Pathology, vol. 26, no. 5, pp. 725-732, 2013.

[355] C. L. Ellis, A. G. Chang, A. Cimino-Mathews et al., "GATA-3 immunohistochemistry in the differential diagnosis of adenocarcinoma of the urinary bladder," The American Journal of Surgical Pathology, vol. 37, no. 11, pp. 1756-1760, 2013.

[356] L. A. Aaltonen, P. Peltomäki, J. P. Mecklin et al., "Replication errors in benign and malignant tumors from hereditary nonpolyposis colorectal cancer patients," Cancer Research, vol. 54, no. 7, pp. 1645-1648, 1994.

[357] J. Sha, J. Bo, J. Pan et al., "Ductal adenocarcinoma of the prostate: immunohistochemical findings and clinical significance," OncoTargets and Therapy, vol. 6, pp. 1501-1506, 2013.

[358] K. Sakamoto, Y. Haga, R. Yoshimura, H. Egami, Y. Yokoyama, and M. Akagi, "Comparative effectiveness of the tumour diagnostics, CA 19-9, CA 125 and carcinoembryonic antigen in patients with diseases of the digestive system," Gut, vol. 28, no. 3, pp. 323-329, 1987.

[359] W. Xu, B. Yu, T. Xu, Z. Xu, H. Cai, and Q. Zou, "Chemotherapy for primary adenocarcinoma of the urinary bladder: case report," Advances in Pharmacoepidemiology \& Drug Safety, vol. 4, p. 180, 2015.

[360] J. E. El Ammari, M. Ahsaini, O. Riyach et al., "Primary signetring cell carcinoma of the urinary bladder successfully 
managed with cisplatin and gemcitabine: a case report," Journal of Medical Case Reports, vol. 7, no. 1, p. 37, 2013.

[361] T. Terada, "An autopsy case of clear cell adenocarcinoma of the urinary bladder," Applied Immunohistochemistry \& Molecular Morphology, vol. 21, no. 4, pp. 371-375, 2013.

[362] T. J. Hugh, S. A. Dillon, G. O'Dowd et al., " $\beta$-catenin expression in primary and metastatic colorectal carcinoma," International Journal of Cancer, vol. 82, no. 4, pp. 504-511, 1999.

[363] G. Afrem, S. Craitoiu, C. Margaritescu, and S. S. Mogoanta, "The study of p53 and CA19-9 prognostic molecular markers in colorectal carcinomas," Romanian Journal of Morphology and Embryology, vol. 51, no. 3, pp. 473-481, 2010.

[364] M. M. Streppel, A. Vincent, R. Mukherjee et al., "Mucin 16 (cancer antigen 125) expression in human tissues and cell lines and correlation with clinical outcome in adenocarcinomas of the pancreas, esophagus, stomach, and colon," Human Pathology, vol. 43, no. 10, pp. 1755-1763, 2012.

[365] H. A. Multhaupt, C. P. Arenas-Elliott, and M. J. Warhol, "Comparison of glycoprotein expression between ovarian and colon adenocarcinomas," Archives of Pathology \& Laboratory Medicine, vol. 123, no. 10, pp. 909-916, 1999.

[366] J. L. Dennis, T. R. Hvidsten, E. C. Wit et al., "Markers of adenocarcinoma characteristic of the site of origin: development of a diagnostic algorithm," Clinical Cancer Research, vol. 11, no. 10, pp. 3766-3772, 2005.

[367] T. J. Jang, J. B. Park, and J. I. Lee, “The expression of CD10 and CD15 is progressively increased during colorectal cancer development," Korean Journal of Pathology, vol. 47, no. 4, pp. 340-347, 2013.

[368] P. Del Rio, P. Crafa, C. Papadia et al., "Is CD10 a reliable marker of invasive colorectal cancer?," Annali Italiani di Chirurgia, vol. 82, no. 4, pp. 279-282, 2011.

[369] T. Terada, "An immunohistochemical study of primary signet-ring cell carcinoma of the stomach and colorectum: I. Cytokeratin profile in 42 cases," International Journal of Clinical \& Experimantal Pathology, vol. 6, no. 4, pp. 703710, 2013.

[370] L. Harbaum, M. J. Pollheimer, P. Kornprat et al., "Keratin 20 a diagnostic and prognostic marker in colorectal cancer?," Histology and Histopathology, vol. 27, no. 3, pp. 347-356, 2012.

[371] R. L. Zimmerman, K. M. Das, F. Fogt, M. Burke, and L. A. Murakata, "The Das-1 immunostain is useful for discriminating metastatic colon adenocarcinoma from cholangiocarcinoma and hepatocellular carcinoma," Oncology Reports, vol. 9, no. 6, pp. 1369-1372, 2002.

[372] R. L. Zimmerman, K. M. Das, M. A. Burke, N. A. Young, C. C. Solomides, and M. Bibbo, "The clinical utility of the Das-1 monoclonal antibody in identifying adenocarcinoma of the colon metastatic to the liver in fine-needle aspiration tissue," Cancer Cytopathology, vol. 96, no. 6, pp. 370-373, 2002.

[373] S. Dorudi, J. P. Sheffield, R. Poulsom, J. M. Northover, and I. R. Hart, "E-cadherin expression in colorectal cancer. An immunocytochemical and in situ hybridization study," The American Journal of Pathology, vol. 142, no. 4, pp. 981-986, 1993.

[374] A. N. Seo, Y. Kwak, D. W. Kim et al., "HER2 status in colorectal cancer: its clinical significance and the relationship between HER2 gene amplification and expression," PLoS One, vol. 9, no. 5, article e98528, 2014.
[375] A. Sartore-Bianchi, L. Trusolino, C. Martino et al., "Dual-targeted therapy with trastuzumab and lapatinib in treatmentrefractory, KRAS codon 12/13 wild-type, HER2-positive metastatic colorectal cancer (HERACLES): a proof-of-concept, multicentre, open-label, phase 2 trial," The Lancet Oncology, vol. 17, no. 6, pp. 738-746, 2016.

[376] Y.S. Yoon, C. S. Yu, T. W. Kim et al., "Mismatch repair status in sporadic colorectal cancer: immunohistochemistry and microsatellite instability analyses," Journal of Gastroenterology and Hepatology, vol. 26, no. 12, pp. 1733-1739, 2011.

[377] J. Shia, "Immunohistochemistry versus microsatellite instability testing for screening colorectal cancer patients at risk for hereditary nonpolyposis colorectal cancer syndrome. Part I. The utility of immunohistochemistry," The Journal of Molecular Diagnostics, vol. 10, no. 4, pp. 293-300, 2008.

[378] Z. Sun, X. Yu, H. Wang, S. Zhang, Z. Zhao, and R. Xu, "Clinical significance of mismatch repair gene expression in sporadic colorectal cancer," Experimental and Therapeutic Medicine, vol. 8, no. 5, pp. 1416-1422, 2014.

[379] D. A. Lawes, T. Pearson, S. Sengupta, and P. B. Boulos, “The role of $M L H 1, M S H 2$ and MSH6 in the development of multiple colorectal cancers," British Journal of Cancer, vol. 93, no. 4, pp. 472-477, 2005.

[380] B. R. Davidson, V. R. Sams, J. Styles, C. Dean, and P. B. Boulos, "Comparative study of carcinoembryonic antigen and epithelial membrane antigen expression in normal colon, adenomas and adenocarcinomas of the colon and rectum," Gut, vol. 30, no. 9, pp. 1260-1265, 1989.

[381] S. Kaur, N. Momi, S. Chakraborty et al., "Altered expression of transmembrane mucins, MUC1 and MUC4, in bladder cancer: pathological implications in diagnosis," PLoS One, vol. 9, no. 3, article e92742, 2014.

[382] O. Kaufmann, T. Deidesheimer, M. Muehlenberg, P. Deicke, and M. Dietel, "Immunohistochemical differentiation of metastatic breast carcinomas from metastatic adenocarcinomas of other common primary sites," Histopathology, vol. 29, no. 3, pp. 233-240, 1996.

[383] M. Kalos, J. Askaa, B. L. Hylander et al., "Prostein expression is highly restricted to normal and malignant prostate tissues," The Prostate, vol. 60, no. 3, pp. 246-256, 2004.

[384] R. E. Emerson and L. Cheng, "Immunohistochemical markers in the evaluation of tumors of the urinary bladder: a review," Analytical and Quantitative Cytology and Histology, vol. 27, no. 6, pp. 301-316, 2005.

[385] A. M. Hanly, M. Redmond, D. C. Winter et al., "Thrombomodulin expression in colorectal carcinoma is protective and correlates with survival," British Journal of Cancer, vol. 94, no. 9, pp. 1320-1325, 2006.

[386] J. A. Bishop, R. Sharma, and P. B. Illei, "Napsin A and thyroid transcription factor-1 expression in carcinomas of the lung, breast, pancreas, colon, kidney, thyroid, and malignant mesothelioma," Human Pathology, vol. 41, no. 1, pp. 20-25, 2010.

[387] A. Matoso, K. Singh, R. Jacob et al., "Comparison of thyroid transcription factor- 1 expression by 2 monoclonal antibodies in pulmonary and nonpulmonary primary tumors," Applied Immunohistochemistry \& Molecular Morphology, vol. 18, no. 2, pp. 142-149, 2010.

[388] H. G. Reis, C. H. D. Metz, H. A. Baba, N. Bornfeld, K. W. Schmid, and K. A. Metz, "TTF-1 (8G7G3/1) positive colon adenocarcinoma: diagnostic implications," Der Pathologe, vol. 32, no. 4, pp. 349-351, 2011. 


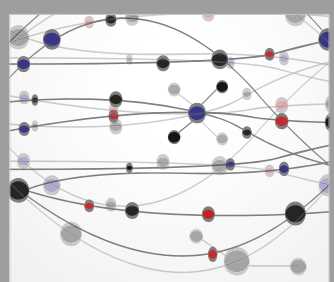

The Scientific World Journal
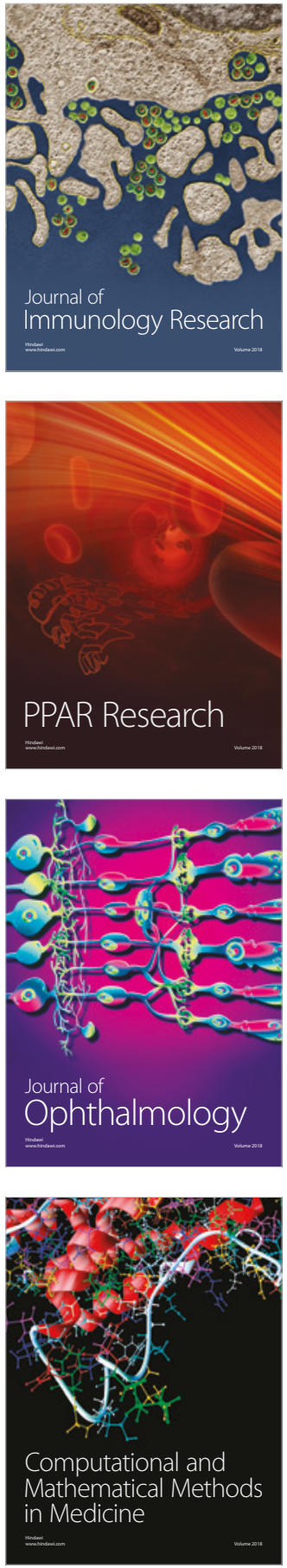

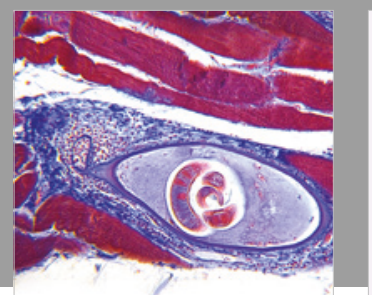

Gastroenterology Research and Practice

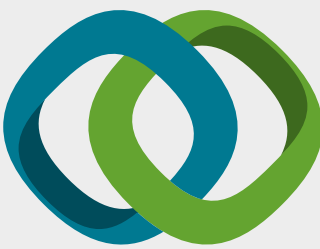

\section{Hindawi}

Submit your manuscripts at

www.hindawi.com
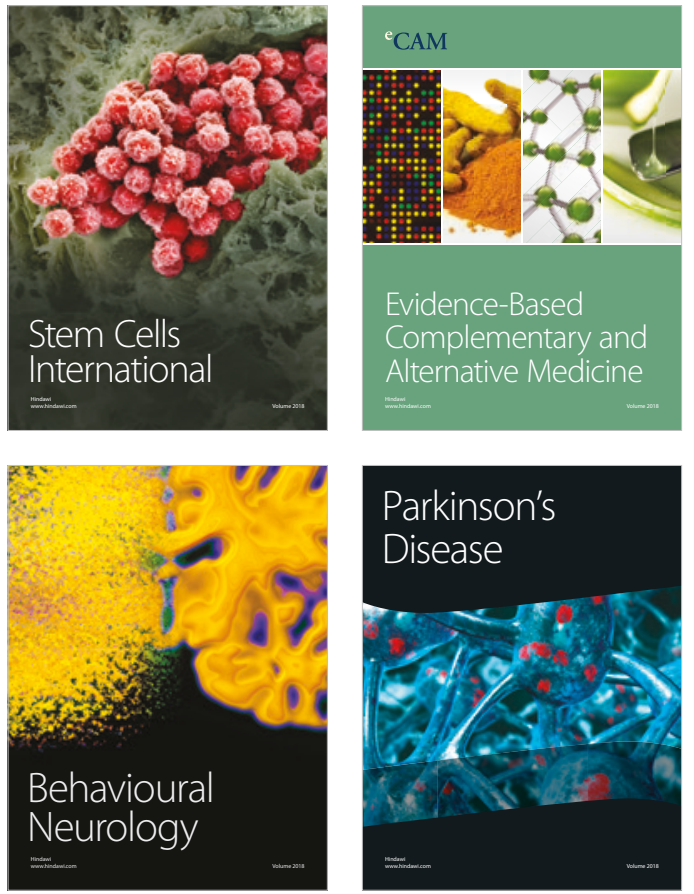

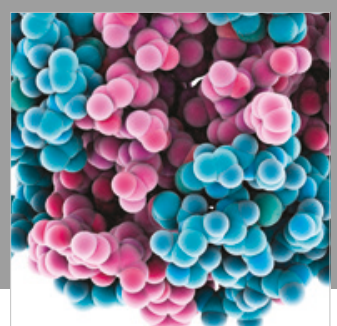

ournal of

Diabetes Research

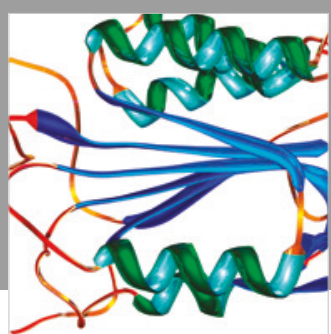

Disease Markers
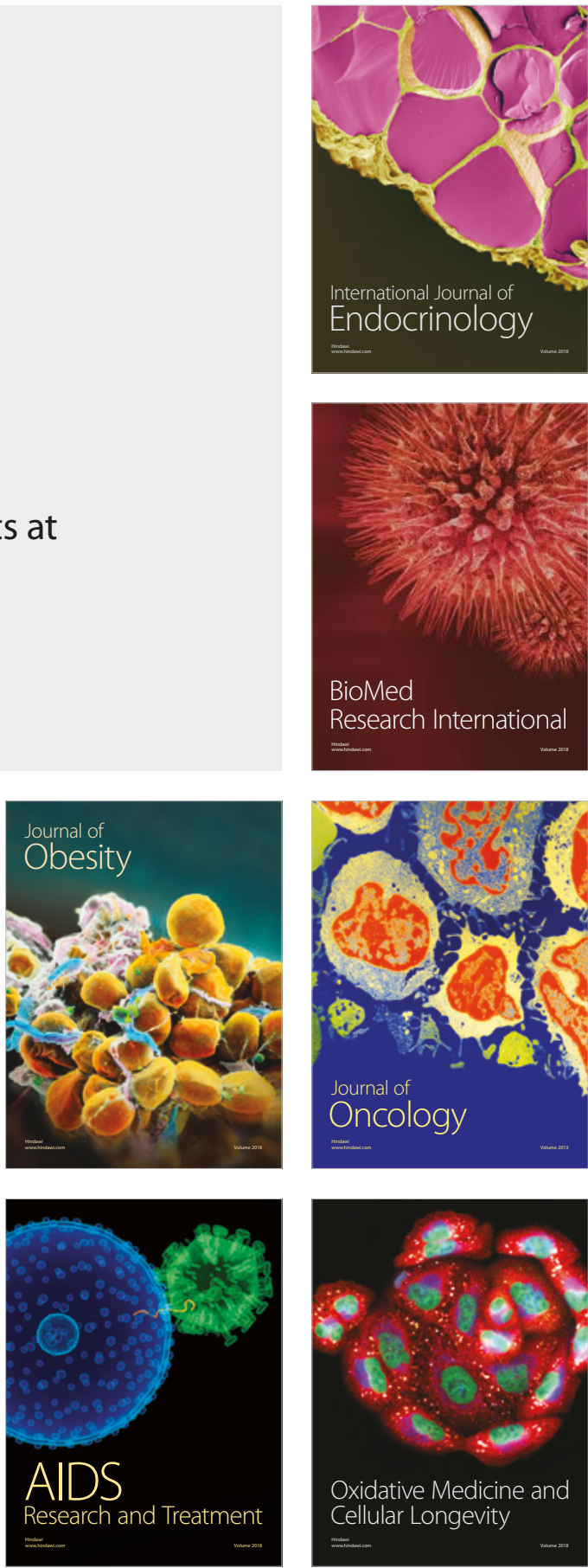